\title{
SOCS Proteins Participate in the Regulation of Innate Immune Response Caused by Viruses
}

\begin{abstract}
Shanzhi Huang 1,2, Ke Liu 1,2, Anchun Cheng ${ }^{1,2,3 *}$, Mingshu Wang 1,2,3, Min Cui ${ }^{3}$, Juan Huang ${ }^{1,2,3}$, Dekang Zhu ${ }^{1,2,3}$, Shun Chen ${ }^{1,2,3}$, Mafeng Liu 1,2,3, Xinxin Zhao 1,2,3, Yin Wu ${ }^{1,2,3}$, Qiao Yang ${ }^{1,2,3}$, Shaqiu Zhang 1,2,3, Xumin Ou ${ }^{1,2,3}$, Sai Mao ${ }^{1,2,3}$, Qun Gao ${ }^{1,2,3}$, Yanling Yu ${ }^{1,2,3}$, Bin Tian ${ }^{1,2,3}$, Yunya Liu ${ }^{1,2,3}$, Ling Zhang ${ }^{1,2,3}$, Zhongqiong Yin ${ }^{3}$, Bo Jing ${ }^{3}$, Xiaoyue Chen ${ }^{1,2,3}$ and Renyong Jia ${ }^{1,2,3 *}$
\end{abstract}

${ }^{1}$ Avian Disease Research Center, College of Veterinary Medicine, Sichuan Agricultural University, Chengdu, China, ${ }^{2}$ Institute of Preventive Veterinary Medicine, Sichuan Agricultural University, Chengdu, China, ${ }^{3}$ Key Laboratory of Animal Disease and Human Health of Sichuan Province, College of Veterinary Medicine, Sichuan Agricultural University, Chengdu, China

OPEN ACCESS

Edited by:

Hans A. R. Bluyssen,

Adam Mickiewicz University, Poland

Reviewed by:

Chien-Kuo Lee,

National Taiwan University, Taiwan

Jeffrey James Babon,

Walter and Eliza Hall Institute of

Medical Research, Australia

*Correspondence:

Renyong Jia

jiary@sicau.edu.cn

Anchun Cheng

chenganchun@vip.163.com

Specialty section

This article was submitted to

Molecular Innate Immunity,

a section of the journal

Frontiers in Immunology

Received: 02 May 2020

Accepted: 24 August 2020

Published: 25 September 2020

Citation:

Huang S, Liu K, Cheng A, Wang M,

Cui M, Huang J, Zhu D, Chen $S$,

Liu $M$, Zhao $X$, Wu Y, Yang $Q$, Zhang S, Ou X, Mao S, Gao Q, Yu Y,

Tian B, Liu Y, Zhang L, Yin Z, Jing B,

Chen $X$ and Jia $R$ (2020) SOCS

Proteins Participate in the Regulation

of Innate Immune Response Caused

by Viruses.

Front. Immunol. 11:558341.

doi: 10.3389/fimmu.2020.558341
The host immune system has multiple innate immune receptors that can identify, distinguish and react to viral infections. In innate immune response, the host recognizes pathogen-associated molecular patterns (PAMP) in nucleic acids or viral proteins through pathogen recognition receptors (PRRs), especially toll-like receptors (TLRs) and induces immune cells or infected cells to produce type I Interferons (IFN-I) and pro-inflammatory cytokines, thus when the virus invades the host, innate immunity is the earliest immune mechanism. Besides, cytokine-mediated cell communication is necessary for the proper regulation of immune responses. Therefore, the appropriate activation of innate immunity is necessary for the normal life activities of cells. The suppressor of the cytokine signaling proteins (SOCS) family is one of the main regulators of the innate immune response induced by microbial pathogens. They mainly participate in the negative feedback regulation of cytokine signal transduction through Janus kinase signal transducer and transcriptional activator (JAK/STAT) and other signal pathways. Taken together, this paper reviews the SOCS proteins structures and the function of each domain, as well as the latest knowledge of the role of SOCS proteins in innate immune caused by viral infections and the mechanisms by which SOCS proteins assist viruses to escape host innate immunity. Finally, we discuss potential values of these proteins in future targeted therapies.

Keywords: suppressor of cytokine signaling proteins, virus, innate immune, cytokine, TLR

\section{INTRODUCTION}

Host cells have gradually evolved multiple cellular signaling networks to detect and respond to viral infections (1). When the host's PRRs binds to PAMP in viral proteins and nucleic acids, it will trigger an antiviral response $(2,3)$ and the intracellular signaling cascades will be initiated, which results in the activation of transcription factors, including IFN regulatory factors (IRFs) and nuclear factor- $\kappa \mathrm{B}(\mathrm{NF}-\kappa \mathrm{B})(1)$. These factors, in turn, will promote and induce gene expression, including IFNs and IFN stimulating genes (ISGs), as well as proinflammatory cytokines and chemokines which are involved in the innate regulation and immune responses $(4,5)$. In the early infection 
of the virus, the host's innate immunity is the first defense mechanism initiated by the host. Before the body produces more specific adaptive immune system protection, innate immune is a crucial component of preventing virus invasion and reproduction.

During the viral infection process, cytokines trigger and deal with inflammation. However, excessive production of cytokines can cause a cytokine storm and excessive host innate immune response can also damage the body. All in all, the negative feedback loop of cells plays a vital role in maintaining the close relationship between cytokine secretion and inhibition. Therefore, the SOCS proteins with negative feedback regulation ability prevents the excessive secretion of cytokines from harming the host (6). An intracellular protein family is constituted by SOCS1-7 proteins and cytokine-inducible SRC homology 2 ( $\mathrm{SH} 2)$ domain-containing proteins (CIS; also known as CISH), some of which play an essential role in regulating the response of immune cells to cytokines (7-9). These proteins regulate signaling pathways at the intracellular level, effectively and specifically inhibit cytokine and growth factor signaling (10). Cytokines, including interleukins (ILs), IFNs and hematopoietic growth factors, play a vital role in innate immune response, adaptive immunity, inflammatory response and cell differentiation and proliferation (11). Also, they can activate the JAK/STAT signaling pathway. SOCS proteins mainly regulate the signal transduction of cytokines by inhibiting JAK activity or targeting ubiquitinated signal transduction factors, thereby avoiding body damage caused by excessive secretion of cytokines $(12,13)$. Studies have shown that the expression of SOCS proteins induced by cytokine stimulation can prevent cytokine signal transduction by inhibiting the JAK/STAT pathway (14-17). This review will explore the central role of SOCS proteins in the virusinduced innate immune response. Emphasis will be placed on the mechanisms involved in SOCS proteins regulating virus-induced innate immune responses.

\section{SOCS PROTEINS COMPOSITION AND FUNCTION OF EACH DOMAIN}

SOCS protein was first discovered in the mid-1990's and was found to be an inhibitor of cytokine-induced STAT cell signaling pathway (18-21). Up to now, there are eight members in SOCS family, namely CIS and SOCS1-SOCS7, each of them contains a central SH2 domain, a variable-length and divergent amino (N) terminal domain and a carboxyl (C) terminal 40 amino acids (aa) module (22). In particular, a sequence rich in proline, glutamic acid, serine and threonine is called PEST motif. So far, only SOCS1, 3, 5, 7 and CIS in the SOCS family contain this sequence $(23,24)$, but it has not been found in SOCS2, 4 and 6 $(25,26)$. Among the domains that constitute the SOCS protein, the C-terminal 40 aa module is called SOCS box. Studies have shown that it binds to elongin $\mathrm{BC}$ in a manner similar to the von Hippel-Lindau protein BC box and shows extended structural conservation with the F box of the Skp2 ubiquitin ligase (27). The SOCS box recruits E2 conjugating enzyme by interacting with elongin BC, cullin-5 and the RING-box-2 (RBX2), which is necessary to complete the negative regulatory process of cytokine signaling $(28,29)$. SOCS1 can inhibit the carcinogenic activity of TEL-JAK2 and this function requires the participation of SOCS box and kinase inhibitory region (KIR) $(30,31)$. In addition, mice lacking SOCS1 completely exhibit similar inflammatory diseases as mice with genetically modified the SOCS box of SOCS1 or mice only lacking the SOCS box of SOCS1 (32). However, the specific role and function of the SOCS box still need further exploration. The SH2 domain at the center of the SOCS proteins determines the target of the SOCS family and except for single-cell fungi, the SH2 domain in most eukaryotes is conserved $(33,34)$. Most importantly, the SH2 domain interacts with the substrate by recognizing phosphorylated tyrosine residues and enhances substrate interaction through the N-terminal extended SH2-subdomain (ESS) (22). The $\mathrm{SH} 2$ domain of various SOCS proteins also perform different functions. For example, the SH2 domain of SOCS1 directly binds to the activation loop of JAK, while the SH2 domains of SOCS2, SOCS3 and CIS can only bind to phosphorylated tyrosine residues on the receptor (14). Although the SH2 domain of SOCS3 does not have high affinity for JAK compared to SOCS1, its KIR structure has a higher affinity for JAK2 than SOCS1 (35). SOCS1 can directly bind to IFN-I receptors, thereby ensuring that SOCS1 has a very effective inhibitory effect on IFN signaling even at low expression levels $(36,37)$. In addition, recent studies have shown that although SOCS1 is an effective inhibitor of the IFN-gamma (IFN- $\gamma$ ) pathway, it cannot directly bind to the IFN- $\gamma$ receptor (38). Unlike other cytokines that suppress the IFN-I response, SOCS1 is related to IFN-I receptors (IFNAR1) specific signals, but not to IFNAR2 specific signals, thereby eliminating tyrosine phosphorylation of the transcription factor STAT1 and reducing antiviral genes duration of expression (39).

Structurally, we can subdivide the SOCS family according to aa residues. The longest aa sequence in the $\mathrm{N}$-terminal region is SOCS4-7 and the shortest is CIS, SOCS1-3 (12, 40,41). So far, the most distinctive members of the SOCS family are CIS, SOCS1-3 (42). CIS and SOCS2 compete with STATs, or sterically block the binding site of STATs on the receptor, thereby inhibiting the activation of STATs, such as STAT5 $(18,43)$. Analysis of SOCS2 knockout (KO) mice uncover that SOCS2 proved to be a relatively specific negative regulator of $\mathrm{GH}$ STAT5 $(44,45)$. SOCS protein not only has the ability to inhibit signal transduction through ubiquitin-mediated degradation of signal transduction compounds. Studies have shown that SOCS1 and SOCS3 also directly inhibit JAK activity through their KIR domains, which are considered to be pseudo-substrate functions and are essential for inhibiting cytokine signaling (46). The KIR of SOCS3 can block the association of substrate and JAK2 by covering the substrate-binding groove of JAK2. Data show that SOCS1 is an efficient inhibitor of JAK1 and JAK2, TYK2, but does not work on JAK3 (38). This can be account for the SH2KIR domains interacting with the evolutionarily conservative "GQM" sequence, which is present in JAK1, JAK2 and TYK2 in all vertebrates, but not in JAK3 (47). Besides, a KIR and KIR mimic peptide called tyrosine kinase inhibitor peptide (TKIP) can inhibit the phosphorylation of its downstream transcription 
factor STAT1 by inhibiting JAK2 signaling $(48,49)$. In short, revealing how the SOCS protein domains combine or interact with external factors may provide a prerequisite for us to better understand how the SOCS family participates in immune regulation and it also provides a much-needed theoretical basis for biomedical treatment.

\section{SIGNALING PATHWAYS INVOLVED IN SOCS PROTEINS \\ SOCS Proteins Regulates JAK/STAT Signaling Pathway}

Once cytokine stimulation occurs, the SOCS proteins will similarly inhibit signal transduction through the JAK/STAT pathway and target the degradation of signal transduction intermediates to prevent further signal transduction in the classical feedback loop $(15,50,51)$ (Figure 1). For example, SOCS1 can regulate the activation of M1-macrophages by inhibiting JAK2/STAT1 and TLR/NF- $\mathrm{B}$ signaling pathway induced by IFN- $\gamma(52,53)$ (Figure 1). In addition, SOCS3 inhibits kinase activity by binding to JAK2, thereby negatively regulating cytokine signaling $(54,55)$ (Figure 1). The analysis by different research groups also show that SOCS3 determines the specificity of IL-6 signaling in macrophages $(22,56,57)$. Experimental macrophages with deletion of SOCS3 gene will lead to the early induction of STAT1-dependent genes instead of the early induction of STAT3-dependent genes. Therefore, IL-6, in this case, induces STAT1 and STAT3 and partially replicates the activity of IFN- $\gamma$. Moreover, SOCS3 ablation leads to the extension and persistence of STAT3 signals. Gene silencing or reducing SOCS3 expression may be the reason for such high STAT3 activity in tumors $(58,59)$. In addition, CIS can negatively regulate cytokines that signal through the JAK/STAT5 pathway, such as erythropoietin, prolactin and IL-3 receptors (60-62) (Figure 1).

The receptor protein will undergo a conformational change after receiving an external signal, causing a series of physiological and biochemical reactions in cell, which are gradually amplified by the intracellular signal transduction pathway. In mammals, the JAK/STAT pathway is the main signaling mechanism of many cytokines (63). The specific process is as follows: In JAK/STAT signal transduction, JAKs (JAK1, JAK2, JAK3 and TYK2) are activated when various ligands bind to cell surface receptors and form mutually phosphorylated dimers. Phosphorylation activated JAK further phosphorylates cell receptors. Once STAT attaches to the receptors, it is phosphorylated and dimerized by JAKs and then translocated into the nucleus to bind to a specific sequence in DNA (64) (Figure 1). STAT inactivation occurs by dephosphorylating proteins along signaling pathways. External factors that interfere with the signal transduction of the JAK/STAT pathway will affect the body's normal immunity, inflammation and cell proliferation, differentiation and apoptosis (63). In addition, failure to properly activate JAK signaling or mutation signalingrelated molecules may lead to inflammation or immune diseases (63).

\section{SOCS Proteins Regulate TLR Signaling Pathway}

PRRs, especially TLRs, identify conserved microbial structures and activate macrophages and dendritic cells (DCs). It has been proposed that SOCS2 may be one of the feedback regulation inhibitors of TLR signal activation in DCs (65). More and more evidence shows that SOCS proteins have a broader function in the regulation of TLR signaling (66, 67) (Figure 1). Moreover, some studies using genetically disrupted KO mice unexpectedly found that SOCS proteins also play an essential role in many immune and pathological processes (42).

\section{SOCS1 and TLR Signaling}

The regulation of TLR signaling is a critical step in the inflammatory response, identifying pathogens and establishing active acquired immunity. Host immune cells have evolved corresponding negative regulatory mechanisms, such as SOCS proteins, to control the excessive immune response caused by collective long-term exposure to LPS. In macrophages, stimulation of CpG-DNA or Lipopolysaccharide (LPS) induces the production of SOCS1 and SOCS3 $(50,68,69)$. SOCS1 protects the host from the lethal LPS response and this has been verified in a model of SOCS1-deficient mice $(66,70,71)$. Studies have shown that SOCS-deficient mice are highly sensitive to LPS stimulation through myeloid differentiation factor 88 (MyD88) -dependent and independent pathways related to IL-1-receptor-associated kinase (IRAK1) (17, 72-74). In addition, SOCS proteins also play a key role in the innate immunity caused by viruses involved in TLR signals. The viruses escape innate immunity by using the negative regulation of SOCS proteins on cytokines. On the one hand, SOCS proteins can regulate TLR-mediated signal transduction. On the other hand, TLR signaling can, in turn, regulate SOCS proteins expression in various kinds of cells $(22,75)$. For example, in pDC cells, hepatitis B virus (HBV) can use SOCS1 up-regulation to inhibit TLR9-mediated IFN- $\alpha$ production, thereby inhibiting intracellular antiviral responses and promoting virus replication (76). Studies have shown that the activation of TLR7 in human plasmacytoid DCs can induce the expression of SOCS1 and SOCS3, while SOCS1 and SOCS3 will strongly inhibit TLR7-mediated IFN-I production (77). In addition, Yu Peng and his colleagues demonstrated that IRF7 combined with SOCS1 and SOCS3 and the SH2 domains of SOCS1 and SOCS3 promoted proteasome-mediated degradation of IRF7 through polyubiquitination related to lysine 48 (77). Moreover, studies have shown that TLR8 couples with SOCS-1 to control the TLR7-mediated antiviral immunity in the mouse central nervous system during West Nile virus (WNV) infection (78). It has also been studied that the binding of hepatitis C virus $(\mathrm{HCV})$ core protein and complement receptor $\mathrm{gClqR}$ on monocytes/macrophages (M/MFs) triggers the expression of PD1 and SOCS-1, which can provide negative signals to the TLRmediated IL-12 expression regulation pathway and IL-12 is a key cytokine connecting innate and acquired immunity (79). The study also showed that the SOCS1 transcript of goose was induced by goIFN and TLR ligands in GEF cells and 


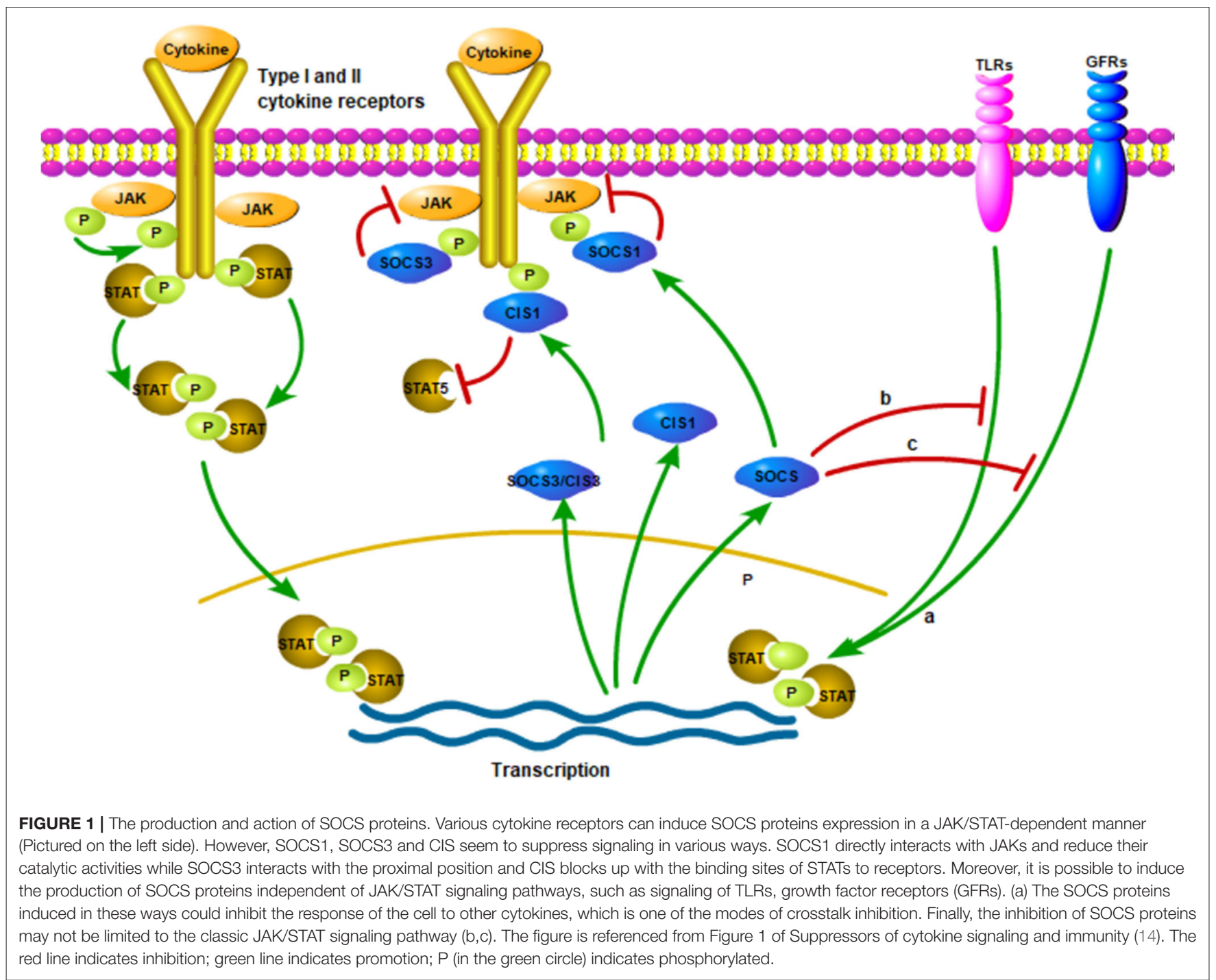

PBMC, respectively. It is worth noting that a high expression level of goose SOCS1 (goSOCS1) was detected after infection with high viral load of Duck Tembusu virus (DTMUV) in vitro and in vivo, which suggests that goSOCS1 may be related to innate and adaptive antiviral immunity (80). The cytokine response is well-regulated by a variety of homeostatic mechanisms, including microRNAs (miRNAs) that can quickly target specific genes involved in the control of immune signaling pathways. Studies have shown that there are several immunerelated miRNAs differentially expressed in monocyte-derived macrophages (MDM) and vitamin D3-treated MDM (D3-MDM) after dengue virus infection. It is worth noting that miR155-5p plays a major role in the cytokine response induced by TLR. The attenuation of miR-155-5p in D3-MDM was confirmed to be related to the increased expression of its target gene SOCS-1. In addition, D3-MDM differentiation induced the down-regulation of surface TLR4, which was related to the decreased secretion of IL-1 $\beta$ derived from TLR4/NF-кB (81).
Several mechanisms for inhibiting cytokine production through SOCS1 have been proposed. The first is that SOCS1 directly affects the signal transduction of the TLR/NF- $\mathrm{B}$ signaling pathway $(66,70)$. SOCS1 attaches to the p65 subunit of NF- $\kappa \mathrm{B}$ and promotes its degradation mediated by ubiquitination. SOCS1 also interacts with Bruton tyrosine-kinase (BTK) to bind to the tyrosine phosphorylated MyD88 adapter-like protein, also known as TIRAP and induces MAL ubiquitination and degradation, which ultimately leads to inhibition of MAL dependence p65 phosphorylation and NF- $\mathrm{B}$ transactivation (39). SOCS1 not only regulates the NF- $\kappa B$ signaling pathway, but also regulates the gene expression of MAPK, JUN N-terminal kinase (JNK) and p38 that are activated by stress by binding to apoptosis signal-regulated kinase 1 (ASK1) (82). Furthermore, the critical mechanism by which SOCS1 inhibits activated macrophages is by inhibiting the secondary activated JAK/STAT pathway $(72,83)$. TRIF-IRF3 pathway can quickly induce IFN- $\beta$ expression and activate JAK/STAT1 within $1 \mathrm{~h}$ after stimulation and then promote the expression of CD40 and other genes 


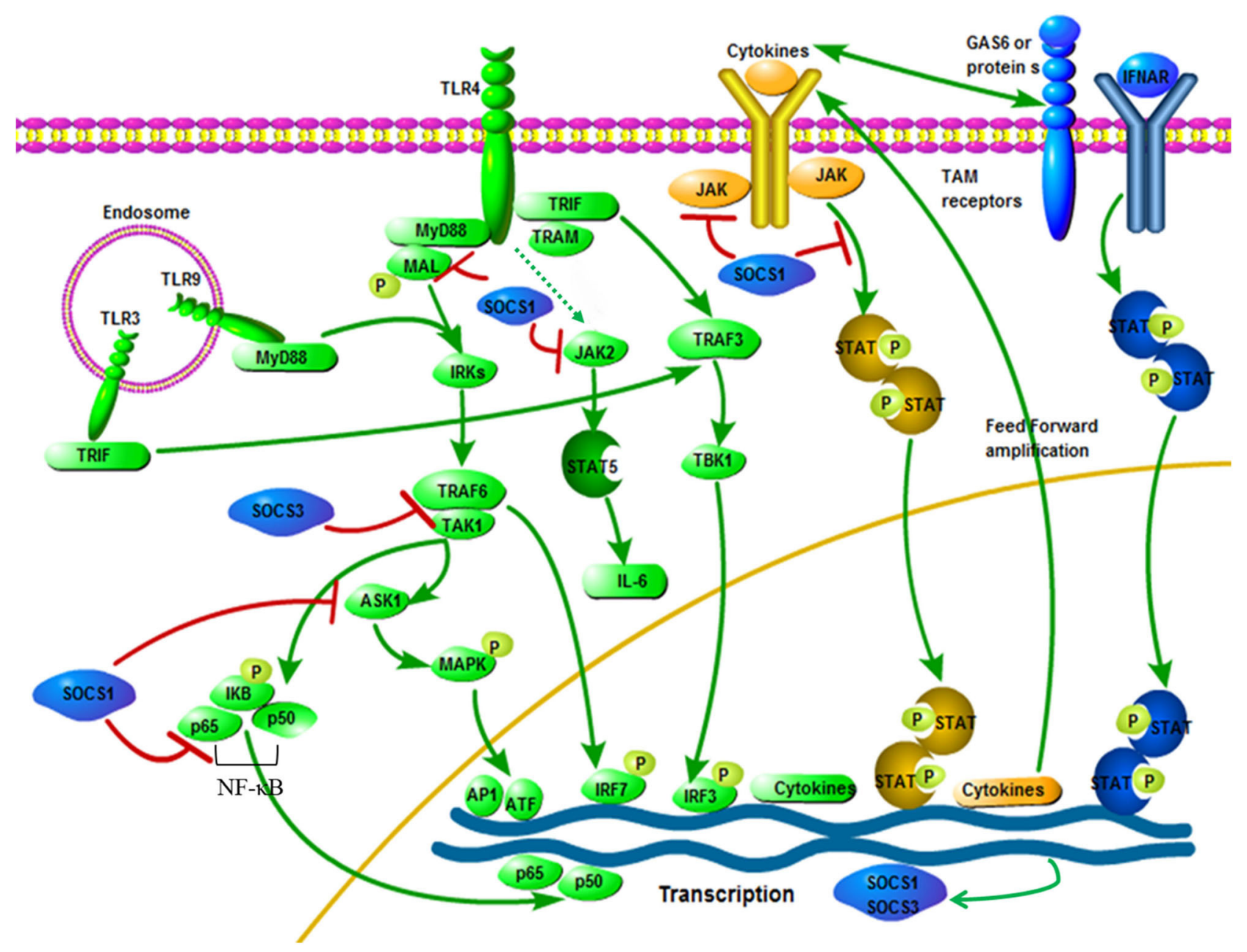

FIGURE 2 | Interactive roles of SOCS1 and SOCS3 in TLR signaling. Pathogen exposure stimulates static cells, which activate the TLR signaling pathway (green). This leads to an initial outbreak of the proinflammatory cytokine, which are then greatly amplified in the feedforward loop through the cytokine receptor signaling pathway (yellow). Cytokine signaling also induces the up-regulation of TAM receptor expression, thereby driving TAM receptor signaling. Besides, TAM receptor signaling requires a synergistic interaction between IFNAR and transcription factor STAT1 (blue). The expression of SOCS1 and SOCS3 are induced, which widely inhibits the cascade of TLR and cytokine receptors, thereby ending the innate immune response (blue). SOCS1 and SOCS3 specific ways to inhibit TLR signaling: After LPS activates TLR4, signals are transmitted through the adaptor proteins including MyD88, MAL, TRIF and TRAM. Through MyD88 and MAL, NF-кB and MAPKs are activated by TRAF6 and TAK1, while IRF3 is activated by TRAM and TRIF. The TRIF-IRF3 pathway can rapidly induce the production of cytokine and activate the JAK/STAT signaling pathway. The JAK2/STAT5 signaling pathway is activated by LPS, which is connected with the IL-6 production. Besides, SOCS1 can inhibit the signaling of these JAK/STAT pathways. Phosphorylated MAL is connected with SOCS1, resulting in polyubiquitination and degradation of the MAL.

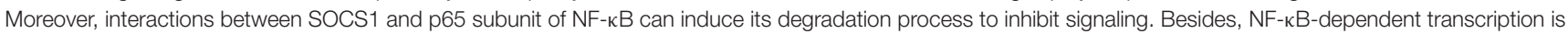
inhibited by SOCS3 by binding inhibition between TRAF6 and TAK1. The figure is referenced from Figure 2 of Immunobiology of the TAM receptors (85). IRAK, IL-1-receptor-associated kinase; TAK1, transforming growth factor- $\beta$ activated kinase 1; AP1, activator protein 1; GAS6, growth arrest-specific 6. Red line indicates inhibition; green line indicates promotion.

with NF-кB. SOCS1 is one of the key inhibitors of this signaling pathway (84) (Figure 2). In addition, it is reported that LPS/TLR4 can activate the JAK2/STAT5 pathway and that the activation of this signaling cascade leads to the massive secretion of pro-inflammatory cytokines TNF- $\alpha$, IL- 6 , IFN- $\beta$ and RANTES, while SOCS1 can be selectively inhibit the JAK2/STAT5 pathway to inhibit the secretion of IL-6 $(67,86,87)$ (Figure 2). It has been reported that SOCS1 regulates IFN- $\beta$-induced JAK/STAT pathway by directly inhibiting STAT1 phosphorylation and indirectly inhibiting TLR4 signaling through IRF3 (88).

\section{SOCS3 and TLR Signaling}

SOCS3 is one of the inducible proteins with abundant expression in macrophages after LPS stimulation and it has been proved that it is also a pivotal regulator of the different levels of activity of IL- 6 and IL-10 after TLR stimulation (89, 90). In addition, LPS-induced STAT1, STAT3 and IL-6 expression increased in SOCS3-deficient macrophages, but had no effect on the activation of NF- $\mathrm{BB}$ and $\operatorname{ERK} 1 / 2(88,91)$. It is generally believed that SOCS3 can indirectly affect the TLR signaling pathway through STAT3 activation, but SOCS3 itself may be one of the mediators of the anti-inflammatory response, 
because both IL-10 and prostaglandin E2 (another potent anti-inflammatory mediator) can induce the up-regulation of SOCS3 protein levels through the cAMP pathway (92). SOCS3 may have a certain effect on the TLR signaling pathway, but this statement is still controversial (93). However, recent studies have shown that SOCS3 can act on the key molecules of TLR signaling and participate in the regulation of TLR signaling. First, at the physiological level, ectopic expression of SOCS3 can inhibit the LPS-mediated expression of TNF and CD40 genes in macrophages $(94,95)$. Secondly, studies have shown that SOCS3 promotes TLR4 response through feedback inhibition of endogenous transforming growth factor-beta1 (TGF- $\beta 1$ )/Smad3 signaling (96). Moreover, there are also reports that SOCS3 can inhibit the activation of tumor necrosis factor receptor associated factor 6 (TRAF6) and TGF- $\beta$ activated kinase (TAK1), which are key factors for the induction and signaling of TLR and IL-1 (52) (Figure 2). Recent studies on acute pancreatitis have also shown that LPS up-regulates the expression levels of SOCS1 and SOCS3 in acinar cells, while SOCS1 and SOCS3 directly interact with TRAF6 and degrade TRAF6 protein through polyubiquitination, thereby counteracting the protective function of TRAF6 in the inflammatory response (97). Mechanism characterization indicated that Ezh2 deficiency directly stimulates SOCS3 expression, thus enhancing Lys48-linked ubiquitination and TRAF6 degradation. As a result, in the absence of Ezh2, TLR-induced MyD88-dependent activation of NF- $\mathrm{B}$ and the expression of pro-inflammatory genes in macrophages/microglia are impaired (98). In addition, studies have shown that MRL-1pr/lpr mice (a Th1-mediated autoimmune disease model) after oral administration of HA900 (a high molecular weight hyaluronic acid) can up-regulate SOCS3 expression in colorectal epithelial cells through TLR4, thereby regulating Th1-mediated autoimmune diseases and inflammation (99). Therefore, SOCS3 may indeed have a regulatory role in TLR signaling. In recent studies, it has been discovered that the cyclic GMP-AMP (cGAMP) synthase (cGAS)-IFN gene stimulator (STING)-mediated cytoplasmic DNA sensing pathway that exists in parallel with TLR9-mediated DNA recognition can also induce the production of SOCS1 and SOCS3, thereby activating the IFN-I inhibitory loop, which indicates that SOCS3 may participate in innate immunity through other ways (100).

\section{SOCS Proteins Regulate Other Signaling Pathways}

SOCS protein is not limited to regulating the classic JAK/STAT signaling pathway, but can also inhibit the signal transduction of cytokines such as insulin and Toll-like receptors and none of them activate the JAK/STAT pathway (101). SOCS4 and 5 regulate epidermal growth factor receptor (EGFR) signaling, of which SOCS5 can regulate viral replication by downregulating EGFR signaling (40). The data suggests that SOCS3 may act directly by preventing JAK activation or mediating ubiquitination of cytokine/growth factor/hormone receptors and subsequent proteasome degradation. Moreover, SOCS3 has been shown to bind to indoleamine dioxygenase (IDO) and mediate the ubiquitination of the complex in DCs. Therefore, SOCS3 antagonizes the IDO-dependent tolerogenic signal in DCs at the post-transcriptional level and converts it into immunogenicity $(102,103)$. SOCS3 can also bind and degrade CD33 (a myeloid cell differentiation antigen) or Siglec3, thereby blocking the proliferation inhibition caused by CD33 (104). In addition, SOCS3 can regulate the body's sensitivity to insulin by binding and targeting proteasome degradation of insulin receptor (IR) or insulin receptor substrate 1 (IRS-1) (105108). It is reported that SOCS3 can also directly interact with SMAD3, thereby inhibiting the response to transforming growth factor- $\beta$ (TGF- $\beta$ ) (96). On the other hand, there are reports that TGF- $\beta$ can induce the expression of SOCS3, thereby promoting the formation of osteoclasts induced by TNF (109). Unexpectedly, it was also found that phosphorylated SOCS3 binds to I $\mathrm{B}$ (NF- $\kappa \mathrm{B}$ inhibitor), hindering its degradation and thus preventing the activation of NF- $\kappa \mathrm{B}$ (110). Studies have also shown that SOCS3 can block IL-1 induced NF- $\kappa$ B and JNK/p38 signaling pathways by binding and inhibiting the signaling of upstream molecule TRAF6 (52). Taken together, the SOCS family are key factors in the feedback regulation of cytokine signaling pathways. Therefore, they play a vital role in regulating inflammation, immunity, growth regulation and determining cell fate.

\section{SOCS PROTEINS REGULATE INNATE IMMUNITY CAUSED BY VIRUSES}

\section{Virus-Induced Innate Immune Process}

During innate immunity, PRRs are involved in identifying and detecting specific viral components and activates corresponding immune signaling pathways in infected cells and other immune cells to enhance the secretion of inflammatory cytokines and IFN-I (111). IFN- $\alpha / \beta$ is the principle cytokine that limits virus replication, while other cytokines, including TNF- $\alpha$, IL- $1 \beta$ and IL-6, recruiting immune cells to the site of infection and causing an inflammatory response. Therefore, it is important to distinguish between self and non-self nucleic acids, especially during viral infection. Recent advances in innate immunity research indicate that this distinction is mostly dependent on PRRs, including the TLR, RIG-I like receptor (RLR) and nucleosides acid-binding oligomeric domain (NOD) like receptor (NLR). These innate immune receptors trigger signaling cascades that are usually integrated with innate responses, such as NF- $\kappa \mathrm{B}$ dependent cytokine responses, IRF dependent IFN- $\alpha / \beta$ responses, inflammatory body/caspase- 1 dependent IL$1 \beta$ responses. NF- $\kappa \mathrm{B}$-dependent and IRF-dependent cytokines are regulated by transcription, while inflammatory bodydependent IL- $1 \beta$ secretion is regulated by transcription and posttranscription (112).

Among various PRRs, TLRs have now been studied in depth. Today, a complex picture of TLR signaling has emerged (113, 114). The critical fact is that microbial stimulation directly binds to TLRs, causing their conformations to change. Among them, heterodimers (TLR1, 2, 6) or homotypes (TLR3, 4, 9) are activated and related to intracellular adaptor molecules. 
Except for TLR3, the central adaptor of all other TLRs is MyD88. For TLR2 and 4, the adaptor/MyD88-adapter-like protein (TIRAP/Mal) containing the TIR domain promotes this binding. In particular, TLR3 and TLR4 can further bind to the Toll/IL-1 receptor domain-containing adaptor inducing IFN- $\beta$ (TRIF), so they can also use TRIF-related molecules (TRAM) as adaptors. Finally, MAPK and NF- $\mathrm{B}$ signaling related molecules are activated through MyD88-dependent signaling (Figure 2). TRIF mainly activates the transcription of IRF3 gene through another pathway, thereby inducing IFN- $\beta$ production and then sends signals in an autocrine or paracrine manner (115). It has also been proposed that other signaling modules are involved in TLR signaling and they are particularly important to activate IRFs family members with specific cell types and ligands way (116). However, once these receptors are activated, corresponding negative feedback regulation will occur to avoid innate immune overreaction. Under such circumstances, the SOCS proteins will exert their negative feedback regulation effect.

\section{Virus Hijacking SOCS Proteins Escapes Innate Immunity}

Cytokines activate the innate immune response and initiate a specific immune response against viruses, but incorrect activation of the immune response can lead to dysregulation of host cytokine signaling during disease infection and ultimately cause tissue and organ dysfunction. The SOCS family are a class of negative regulators induced by cytokines, which can block the signal transduction of cytokines, thereby avoiding the body's excessive immune response (117). SOCS1 overexpression leads to a decrease in the phosphorylation levels of JAK1, TYK2 and STAT1 and inhibits the antiviral and antiproliferative responses induced by IFN-I $(118,119)$. Many innate or adaptive immune transcription factors can induce the production of SOCS proteins, but under normal physiological conditions, the most significant SOCS proteins production is induced by cytokines such as IFN-I, IFN-II and IL-6 through the JAK/STAT signaling pathway $(21,120-123)$. SOCS1 ablated cells and SOCS1 ${ }^{-/}$mice are resistant to viral infection (37). It seems that the negative regulation of other cytokine pathways is the main role of SOCS3, such as the regulation of IL-6 family cytokine signaling (55), but it has also been shown that SOCS3 can inhibit the antiviral function of IFNs.

Due to the immunomodulatory effect of SOCS proteins, it is normal to think that infectious micro-organisms can manipulate the host's SOCS proteins to escape innate immunity. Studies show that Porcine Reproductive and Respiratory Syndrome virus (PRRSV) can choose SOCS1 to evade the host's immune response and SOCS1 can inhibit the expression levels of ISGs and IFN- $\beta$ to promote viral replication (124). Furthermore, when HCV and herpes simplex virus 1 (HSV-1) infect human hepatoma cells and amniotic cells, respectively, they can abrogate IFN- $\alpha / \beta$ signaling by enhancing SOCS3 protein expression $(125,126)$. Influenza virus infection mainly inhibits JAK/STAT pathway signaling by up-regulating the expression of SOCS1 and SOCS3, thereby disrupting the host antiviral defense mechanism mediated by IFN-I and IFN-II $(127,128)$. Studies have shown that the nonstructural protein 1 (NS1) of respiratory syncytial virus (RSV) inhibits the antiviral response induced by IFN and the production of chemokines by inducing the up-regulation of SOCS1 and SOCS3 (129). The SOCS proteins have been extensively studied and have been known for many years to induce SOCS proteins by activating cytokine receptors, primarily through the activation of IFNAR $(42,130)$. For example, the production of a large amount of inflammatory factors during influenza A virus (IAV) infection leads to the expression of SOCS1 and SOCS3 through RIG-I/MAVS/IFNAR1-dependent pathways, which ultimately inhibited the antiviral response (131). Moreover, TLR-mediated IFNAR-STAT1 signaling leads to the up-regulation of TAM (Tyro3, Axl and Mer) receptor tyrosine kinases, which in turn tampers with the IFNAR-STAT1 box and ultimately induces the expression of SOCS1 and SOCS3 to suppress cytokine and TLR signals transduction (132). This mechanism also exists in the innate immunity caused by the virus. During Zika virus (ZIKV) infection, Axl regulates the expression of SOCS1 in a STAT1/STAT2-dependent manner, thereby antagonizing IFN-I-mediated antiviral immunity, promoting virus infection and replication (133). Similarly, enveloped viruses such as WNV can disrupt the DC's innate immune response through the negative regulatory mechanism of IFN-I signaling mediated by AXL-SOCS1 (134). Thus, viruses can inhibit IFNAR signaling through the inhibitory protein SOCS1 through AXL and other TAM receptors, hence evading the innate immune response pathway activated by the TLR receptor and promoting its infection (85). The SOCS proteins not only regulate the production of IFN-I and IFN-II but also IFN-III. Although the host secretes IFN-I and IFN- $\lambda$ during viral infection to suppress viral infection. Nevertheless, the main IFN induced in the nasal epithelium during respiratory virus infection is IFN- $\lambda$ instead of IFN-I and its production can also help prevent respiratory virus infection (135). Studies have shown that the inhibition of IFN- $\lambda$ signal by SOCS-1 induced by influenza virus leads to an increase in the adaptability of host IFN- $\lambda$ expression, thereby protecting cells from virus infection, but it leads to the overproduction of IFN- $\lambda$, which ultimately results in the sabotage of antiviral response (136). Recent studies have also shown that IL-17A attenuates IAV-induced IFN- $\lambda$ expression by enhancing the expression of SOCS1 and SOCS3 to inhibit the autocrine signaling circuit in human airway epithelial cells (137). Similar reports have been reported in flaviviruses, ZIKV infection causes up-regulated expression of SOCS1 and SOCS3, thereby inhibiting RLR dependent IFN-I and IFN-III secretion, indicating that in ZIKV infection, SOCS proteins may regulate viral replication by modulating the antiviral innate immune response (138). In fact, immune evasion of various viruses, such as HBV (139), $\operatorname{HCV}(79,125)$, human immunodeficiency virus (HIV) (140143), Semliki forest virus (37), coxsackievirus (144), RSV (145), Ebola virus (146), IAV (147), HSV-1 (126, 148, 149), Varicellazoster virus (VZV) (150), Japanese encephalitis virus (JEV) (151) and Epstein-Barr virus (EBV) (152) by targeting SOCS1 and/or SOCS3 has been reviewed elsewhere $(153,154)$. Studies have also shown that in $\mathrm{HCV}$ infection, $\mathrm{HCV}$ protein $\mathrm{P} 7$ mediates the up-regulation of SOCS3 through the JAK/STAT signaling pathway and MAPK pathway, while up-regulation of SOCS3 suppresses TNF- $\alpha$-mediated I $B$ degradation and subsequent 
NF- $\kappa \mathrm{B}$ promoter activity, which leads to the inhibition of the inflammatory response during HCV infection $(155,156)$. HSV is the second virus found to induce the production of host SOCS3 protein (126). Studies have shown that JAK signal will stimulate the expression of SOCS3 in HSV-infected FL cells and the overexpression of SOCS3 will down-regulate the antiviral effect mediated by IFN- $\alpha / \beta$ signals, thereby promoting virus replication (148) (Table $\mathbf{1}$ ).

Some recent studies have also explored the effects of SOCS2 gene knockout on viral infection during viral infections such as HSV-1 (157), HSV-2 (158), or bovine herpesvirus type 5 (BHV-5) (159). For example, under the same infection with HSV-1, SOCS2 gene-deficient mice showed less severe immune cell infiltration, encephalitis and neuroinflammation than wildtype C57BL/6 mice (157). Unlike HSV-1 infection, SOCS2 KO mice have worsened meningoencephalitis compared to wild-type animals during $\mathrm{BHV}-5$ infection, indicating that SOCS2 protein has a protective effect on intracranial BHV-5 infection (159). There are also reports on SOCS5 in the regulation of influenza virus infection. After experimental infection with IAV, SOCS5 deficient mice showed more severe viral infections than the control group, such as increased virus titers and weight loss in mice, further research found that SOCS5 may play a vital role in restricting IAV infection of airway epithelium by regulating the EGFR signaling pathway (160). In the future, there may be more viruses affecting SOCS proteins. In general, due to the negative regulation of SOCS in the cytokine signaling pathway, the virus manipulates the expression of various SOCS genes to suppress antiviral signals and evade innate immune responses.

\section{MicroRNAs Regulate Innate Immunity Through SOCS Proteins}

Recently, miRNAs are increasingly considered as an essential factor that regulates the interaction between virus and host (161), many studies have also shown that there is a change in the miRNAs expression profile of the host or virus in viral infections

TABLE 1 | Virus Hijacking SOCS Proteins Escapes Innate Immunity.

\begin{tabular}{|c|c|c|}
\hline Virus & Target socs & Effect \\
\hline PRRSV & $\uparrow S O C S 1$ & $\begin{array}{l}\downarrow \text { IFN- } \beta \text {, ISGs } \\
\uparrow \text { viral replication }\end{array}$ \\
\hline $\mathrm{HCV}$ & $\uparrow$ SOCS3 & $\begin{array}{l}\downarrow \mathrm{IFN}-\alpha / \beta \\
\uparrow \text { viral replication }\end{array}$ \\
\hline HSV & $\uparrow$ SOCS3 & $\begin{array}{l}\downarrow \mathrm{IFN}-\alpha / \beta \\
\uparrow \text { viral replication }\end{array}$ \\
\hline IAV & $\uparrow$ SOCS1, 3 & $\begin{array}{l}\downarrow \text { type I and type II IFN, } \\
\uparrow I F N-\lambda \\
\uparrow \text { viral replication }\end{array}$ \\
\hline RSV & $\uparrow S O C S 1,3$ & $\begin{array}{l}\downarrow \text { IFN signal, chemokines, ISGs } \\
\uparrow \text { viral replication }\end{array}$ \\
\hline WNV & $\uparrow S O C S 1$ & $\begin{array}{l}\downarrow \text { type I I IFN } \\
\uparrow \text { viral replication }\end{array}$ \\
\hline ZIKA & $\uparrow$ SOCS1, SOCS3 & $\begin{array}{l}\downarrow \text { type I and type III interferon } \\
\uparrow \text { viral replication }\end{array}$ \\
\hline $\mathrm{HCV}$ & $\uparrow$ SOCS3 & $\downarrow N F-\kappa B$, inflammatory response \\
\hline
\end{tabular}

$\uparrow$ increases; $\downarrow$ decreases and some of these miRNAs can regulate the expression of SOCS proteins to regulate innate immune pathways. miRNA mainly regulates the expression of immune-related genes in the body by targeting the 3'-untranslated region (3'-UTR) of the target gene, thereby inhibiting or promoting the antiviral response mediated by downstream cascade signals (162-169). On the one hand, the virus itself can generate viral miRNAs, or the virus infection can lead to changes in the expression profile of host miRNAs (170-174). On the other hand, some viral miRNAs and altered host miRNAs can directly target the viral genome or indirectly target host genes to regulate viral replication (175-177). For example, in infectious bursal disease virus (IBDV) infection, the host miR-155 can inhibit the expression of SOCS1 and TANK to promote IFN-I-mediated antiviral response, thereby inhibiting IBDV replication (169). Besides, the authors found that miR-130b of the host can also inhibit IBDV replication by targeting the viral genome and the host's SOCS5 protein, similarly, miR-454 can inhibit IBDV replication by targeting the IBDV genome and SOCS6 $(169,178)$. In IBDV infection, gga-miR-27b-3p ectopically expressed in DF-1 cells can directly inhibit SOCS3 and SOCS6 and promote the expression of chicken IRF3, NF- $\kappa$ B and IFN- $\beta$ genes, thereby inhibiting IBDV replication (179). HCV infected cells cause up-regulation of miR221 expression, which inhibit the expression of SOCS1 and SOCS3, thereby promoting the JAK/STAT signaling pathway and enhancing the anti-HCV effect of IFN (180). JEV infection in human brain microglial cells (CHME3) down-regulated the expression of miR-432, which reduced the phosphorylation of STAT1 and ISRE activity by negatively regulating the expression of SOCS5 and ultimately promoted cell inflammation and virus replication (181). Transmissible gastroenteritis virus (TGEV) infection can cause ER (endoplasmic reticulum) stress and increase inositol-requiring enzyme $1 \alpha$ (IRE1 $\alpha)$ expression which downregulates the abundance of host miR-30a-5p that normally enhances antiviral responses by targeting SOCS1 and SOCS3 expression, thus facilitating TGEV replication (182). Moreover, in LTEP- $\alpha-2$ and SPC- $\alpha-1$ human lung cancer cell lines experimentally infected with HSV-2, the virally-encoded

\begin{tabular}{|c|c|c|c|}
\hline Virus & miRNA & Target SOCS & Effect \\
\hline IBDV & $\uparrow \mathrm{miR}-155$ & $\downarrow$ SOCS1 & $\begin{array}{l}\uparrow \text { type I IFN } \\
\downarrow \text { viral replication }\end{array}$ \\
\hline IBDV & $\uparrow m i R-130 b$ & $\downarrow$ SOCS5 & $\begin{array}{l}\uparrow \text { IFN- } \beta \\
\downarrow \text { viral replication }\end{array}$ \\
\hline IBDV & $\uparrow \mathrm{miR}-454$ & $\downarrow$ SOCS6 & $\downarrow$ viral replication \\
\hline IBDV & $\uparrow m i R-27 b-3 p$ & $\downarrow$ SOCS3, 6 & $\uparrow$ IFN- $\beta$, IRF3 and NF-кB \\
\hline $\mathrm{HCV}$ & $\uparrow \mathrm{miR}-221$ & $\downarrow$ SOCS1, SOCS3 & $\begin{array}{l}\uparrow \text { anti-HCV IFN, } \\
\uparrow \text { JAK/STAT signaling }\end{array}$ \\
\hline JEV & $\downarrow \mathrm{miR}-432$ & $\uparrow$ SOCS5 & $\begin{array}{l}\uparrow \text { phosphorylation of STAT1, } \\
\uparrow \text { cellular inflammation, } \\
\uparrow \text { viral replication }\end{array}$ \\
\hline TEGV & $\downarrow$ miR-30a-5p & $\uparrow$ SOCS1, SOCS3 & $\downarrow$ type I IFN \\
\hline HSV-2 & $\uparrow H s v 2-m i R-H 9-5 p$ & $\downarrow$ SOCS2 & $\uparrow$ viral replication \\
\hline
\end{tabular}

$\uparrow$ increases; $\downarrow$ decreases. 
microRNA Hsv2-miRH9-5p targets and inhibits SOCS2, thereby driving experimental tumor metastasis in these cell lines (158) (Table 2). Taken together, miRNA participates in the immune pathway caused by the virus by regulating the expression of the SOCS gene during viral infection and this also provides new ideas for our future treatment plans and clinical applications.

\section{THERAPEUTIC IMPLICATIONS}

Since SOCS proteins play a key regulatory role in cytokines (especially IFNs), increasing studies have shown that viruses utilize the function of host SOCS proteins to escape the host's immune process, so these proteins also have great therapeutic potential (153). One therapeutic strategy to consider would be suppression of SOCS proteins levels or function during viral infection. A small synthetic peptide containing a phosphorylation activation loop of JAK2 and capable of isolating SOCS is pJAK2, which is also an antagonist of SOCS1 and SOCS3 (48). The peptide has been shown to have therapeutic effects in keratinocytes infected with HSV-1 and can also prevent mice from lethal doses of vaccinia virus, IAV and encephalomyocarditis virus infections $(149,183,184)$. Moreover, the use of siRNA to silence SOCS1 in DCs allows these cells to better elicit anti-HIV-1 antibody and $\mathrm{T}$ cell responses in mice (140). In addition, miRNAs are increasingly considered to be regulators of SOCS expression (185). For example, studies have shown that inhibiting the expression of miRNA-122 to enhance promoter methylation to inhibit the expression of SOCS3 is a promising option for the treatment of HCV (186-188). Until recently, IL-7 therapy has also been shown to improve the immune response to persistent infections caused by HIV, HBV and HCV by targeting SOCS3 (189). Although these examples are limited and preliminary, they suggest that manipulation of the SOCS proteins may provide an effective mechanism to inhibit viral replication during viral infection. On the other hand, overexpression of SOCS protein through viral vectors may be an effective strategy to inhibit inflammation response. In a study using mice with experimental arthritis, it was found that compared with the control group, injection of recombinant adenovirus carrying SOCS3 cDNA in the joint cavity can significantly reduce the severity of arthritis and joint swelling (190). In addition, in order to suppress the host's inflammatory response, a method of exogenously expressing SOCS1 with therapeutic viral vectors has been proposed $(191,192)$. This strategy may expand the scope and efficacy of viral vectors in the future.

Since the deletion or inhibition of SOCS1 and SOCS3 in $\mathrm{T}$ cells or myeloid cells enhances anti-tumor immunity, SOCS inhibitors may be ideal drugs for targeting immune checkpoints controlled by cytokines (193). One method is to silence the expression of SOCS proteins in DCs or CTL through specific siRNA to enhance anti-tumor immunity (194). But under normal circumstances, silencing the expression of SOCS1 and SOCS3 genes will exacerbate canceration. In addition, SOCS1 gene silencing may promote JAK/STAT signal transduction, which leads to an increase in the body's response to cytokines and ultimately promotes the survival and expansion of myeloma bone marrow cells (195). At the same time, the overexpression of SOCS proteins in tumor cells is another way to inhibit tumor growth by inhibiting tumor-promoting STATs (196, 197). For example, as a mimetic of SOCS proteins, TKIP can effectively inhibit JAK2-mediated STAT1 phosphorylation and proliferation of prostate cancer cells $(48,198)$. Platelet factor 4 enhances the expression of SOCS3 protein, thereby inhibiting STAT3 activation and inducing apoptosis in myeloma (199). TSA increases the expression of SOCS1 and SOCS3 in human colorectal cancer cells and inhibits the growth of CRC (200). New preclinical data show the potential of using gene therapy to induce SOCS3 overexpression in castration-resistant prostate cancer (CRPC), which may work by attenuating the IL-6JAK/STAT signaling pathway (201). Taken together, these studies encourage the clinical application of new therapies that modulate SOCS proteins expression or function.

\section{CONCLUDING REMARKS}

In the past two decades, with the development of science and technology, further understandings have been made in the functional mechanisms and regulatory role in the innate immunity of SOCS proteins. At the same time, pathogens can also achieve innate immune escape by manipulating SOCS proteins and examples of viruses, bacteria and parasites have been found. Although many studies have been disclosed relationships between mRNA and protein levels of SOCS family and immune and inflammatory diseases, the regulatory mechanisms of expression levels of SOCS family members are still unknown. Due to the role of SOCS proteins in the immune response caused by viruses has not been fully elucidated, thus limiting the scientific and clinical advances made by immunologists and microbiologists. Therefore, further research on the function of SOCS proteins may reveal that these proteins have more unexpected effects in the immune system signaling pathway. These findings can also bring more scientific theoretical basis for the treatment of diseases.

\section{AUTHOR CONTRIBUTIONS}

$\mathrm{SH}$ carried out the literature search and exploration and completed most of the manuscript writing. RJ and AC helped with the completion of the manuscript and coordination of the project. KL, MW, MC, JH, DZ, SC, ML, XZ, YW, QY, SZ, XO, SM, QG, YY, BT, YL, LZ, ZY, BJ, and XC read and edited the manuscript. All authors contributed to the article and approved the submitted version.

\section{FUNDING}

This work was supported by the National Natural Science Foundation of China (31872475 and 31902267), Sichuan Veterinary Medicine and Drug Innovation Group of China Agricultural Research System (SCCXTD-2020-18), and China Agricultural Research System (CARS-42-17). 


\section{REFERENCES}

1. Katze MG, Fornek JL, Palermo RE, Walters K-A, Korth MJ. Innate immune modulation by RNA viruses: emerging insights from functional genomics. Nat Rev Immunol. (2008) 8:644-54. doi: 10.1038/nri2377

2. Saito T, Gale M. Principles of intracellular viral recognition. Curr Opin Immunol. (2007) 19:17-23. doi: 10.1016/j.coi.2006.11.003

3. Thompson AJV, Locarnini SA. Toll-like receptors, RIG-I-like RNA helicases and the antiviral innate immune response. Immunol Cell Biol. (2007) 85:43545. doi: 10.1038/sj.icb.7100100

4. Hilton DJ, Richardson RT, Alexander WS, Viney EM, Willson TA, Sprigg NS, et al. Twenty proteins containing a C-terminal SOCS box form five structural classes. Proc Natl Acad Sci USA. (1998) 95:114-9. doi: 10.1073/pnas. 95.1.114

5. de Veer MJ, Holko M, Frevel M, Walker E, Der S, Paranjape JM, et al. Functional classification of interferon-stimulated genes identified using microarrays. J Leukocyte Biol. (2001) 69:912-20. doi: 10.1189/jlb.69.6.912

6. Alston CI, Dix RD. SOCS and herpesviruses, with emphasis on cytomegalovirus retinitis. Front Immunol. (2019) 10:732. doi: 10.3389/fimmu.2019.00732

7. Fletcher J, Starr R. The role of suppressors of cytokine signalling in thymopoiesis and T cell activation. Int J Biochem Cell Biol. (2005) 37:177486. doi: 10.1016/j.biocel.2005.04.005

8. Naka T, Fujimoto M, Tsutsui H, Yoshimura A. Negative regulation of cytokine and TLR signalings by SOCS and others. Adv Immunol. (2005) 87. doi: 10.1016/S0065-2776(05)87003-8

9. Davey GM, Heath WR, Starr R. SOCS1: a potent and multifaceted regulator of cytokines and cell-mediated inflammation. Tissue Antig. (2006) 67:19. doi: 10.1111/j.1399-0039.2005.00532.x

10. Linossi EM, Babon JJ, Hilton DJ, Nicholson SE. Suppression of cytokine signaling: the SOCS perspective. Cytokine Growth Factor Rev. (2013) 24:2418. doi: 10.1016/j.cytogfr.2013.03.005

11. O'Shea JJ, Gadina M, Schreiber RD. Cytokine signaling in 2002: new surprises in the Jak/Stat pathway. Cell. (2002) 109:S121-31. doi: 10.1016/S0092-8674(02)00701-8

12. Trengove MC, Ward AC. SOCS proteins in development and disease. Am J Clin Exp Immunol. (2013) 2:1-29. Available online at: http://dro.deakin.edu. au/view/DU:30059965

13. Hao L-X, Sun L. Comparative analysis of the expression patterns of eight suppressors of cytokine signaling in tongue sole, cynoglossus semilaevis. Fish Shellfish Immunol. (2016) 55:595-601. doi: 10.1016/j.fsi.2016. 06.034

14. Kubo M, Hanada T, Yoshimura A. Suppressors of cytokine signaling and immunity. Nat Immunol. (2003) 4:1169-76. doi: 10.1038/ni1012

15. Elliott J, Johnston JA. SOCS: role in inflammation, allergy and homeostasis. Trends Immunol. (2004) 25:434-40. doi: 10.1016/j.it.2004.05.012

16. Ilangumaran S, Ramanathan S, Rottapel R. Regulation of the immune system by SOCS family adaptor proteins. Semin Immunol. (2004) 16:35165. doi: 10.1016/j.smim.2004.08.015

17. Croker BA, Kiu H, Nicholson SE. SOCS regulation of the JAK/STAT signalling pathway. Semin Cell Dev Biol. (2008) 19:414-22. doi: 10.1016/j.semcdb.2008.07.010

18. Yoshimura A, Ohkubo T, Kiguchi T, Jenkins NA, Gilbert DJ, Copeland NG, et al. A novel cytokine-inducible gene CIS encodes an $\mathrm{SH} 2$-containing protein that binds to tyrosine-phosphorylated interleukin 3 and erythropoietin receptors. EMBO J. (1995) 14:2816-26. doi: 10.1002/j.1460-2075.1995.tb07281.x

19. Endo TA, Masuhara M, Yokouchi M, Suzuki R, Sakamoto H, Mitsui K, et al. A new protein containing an $\mathrm{SH} 2$ domain that inhibits JAK kinases. Nature. (1997) 387:921-4. doi: 10.1038/43213

20. Naka T, Narazaki M, Hirata M, Matsumoto T, Minamoto S, Aono A, et al. Structure and function of a new STAT-induced STAT inhibitor. Nature. (1997) 387:924-9. doi: 10.1038/43219

21. Starr R, Willson TA, Viney EM, Murray LJ, Rayner JR, Jenkins BJ, et al. A family of cytokine-inducible inhibitors of signalling. Nature. (1997) 387:91721. doi: $10.1038 / 43206$
22. Yoshimura A, Naka T, Kubo M. SOCS proteins, cytokine signalling and immune regulation. Nat Rev Immunol. (2007) 7:454-65. doi: $10.1038 /$ nri2093

23. Rogers S, Wells R, Rechsteiner M. Amino acid sequences common to rapidly degraded proteins: the PEST hypothesis. Science. (1986) 234:3648. doi: $10.1126 /$ science. 2876518

24. Babon JJ, Yao S, DeSouza DP, Harrison CF, Fabri LJ, Liepinsh E, et al. Secondary structure assignment of mouse SOCS3 by NMR defines the domain boundaries and identifies an unstructured insertion in the $\mathrm{SH} 2$ domain. FEBS J. (2005) 272:6120-30. doi: 10.1111/j.1742-4658.2005.05010.x

25. Babon JJ, McManus EJ, Yao S, DeSouza DP, Mielke LA, Sprigg NS, et al. The structure of SOCS3 reveals the basis of the extended $\mathrm{SH} 2$ domain function and identifies an unstructured insertion that regulates stability. Mol Cell. (2006) 22:205-16. doi: 10.1016/j.molcel.2006.03.024

26. Williams JJL, Alotaiq N, Mullen W, Burchmore R, Liu L, Baillie GS, et al. Interaction of suppressor of cytokine signalling 3 with cavin1 links SOCS3 function and cavin-1 stability. Nat Commun. (2018) 9:168. doi: 10.1038/s41467-017-02585-y

27. Bullock AN, Debreczeni JE, Edwards AM, Sundström M, Knapp S. Crystal structure of the SOCS2-elongin C-elongin B complex defines a prototypical SOCS box ubiquitin ligase. Proc Natl Acad Sci USA. (2006) 103:763742. doi: 10.1073/pnas.0601638103

28. Kamura T, Maenaka K, Kotoshiba S, Matsumoto M, Kohda D, Conaway RC, et al. VHL-box and SOCS-box domains determine binding specificity for Cul2-Rbx1 and Cul5-Rbx2 modules of ubiquitin ligases. Genes Dev. (2004) 18:3055-65. doi: 10.1101/gad.1252404

29. Linossi EM, Nicholson SE. Kinase inhibition, competitive binding and proteasomal degradation: resolving the molecular function of the suppressor of cytokine signaling (SOCS) proteins. Immunol Rev. (2015) 266:12333. doi: $10.1111 /$ imr.12305

30. Frantsve J, Schwaller J, Sternberg DW, Kutok J, Gilliland DG. Socs1 inhibits TEL-JAK2-mediated transformation of hematopoietic cells through inhibition of JAK2 kinase activity and induction of proteasome-mediated degradation. Mol Cell Biol. (2001) 21:3547-57. doi: 10.1128/MCB.21.10.3547-3557.2001

31. Kamizono S, Hanada $\mathrm{T}$, Yasukawa $\mathrm{H}$, Minoguchi $\mathrm{S}$, Kato $\mathrm{R}$, Minoguchi $M$, et al. The SOCS box of SOCS-1 accelerates ubiquitin-dependent proteolysis of TEL-JAK2. J Biol Chem. (2001) 276:12530-8. doi: 10.1074/jbc.M010074200

32. Zhang JG, Metcalf D, Rakar S, Asimakis M, Greenhalgh CJ, Willson TA, et al. The SOCS box of suppressor of cytokine signaling-1 is important for inhibition of cytokine action in vivo. Proc Natl Acad Sci USA. (2001) 98:13261-5. doi: 10.1073/pnas.231486498

33. Pawson $\mathrm{T}$, Nash P. Protein-protein interactions define specificity in signal transduction. Genes Dev. (2000) 14:1027-47. doi: 10.1016/j.ejsobi.2008.07.003

34. Liu BA, Jablonowski K, Raina M, Arcé M, Pawson T, Nash PD. The human and mouse complement of $\mathrm{SH} 2$ domain proteins-establishing the boundaries of phosphotyrosine signaling. Mol Cell. (2006) 22:85168. doi: 10.1016/j.molcel.2006.06.001

35. Sasaki A, Yasukawa H, Suzuki A, Kamizono S, Syoda T, Kinjyo $\mathrm{I}$, et al. Cytokine-inducible $\mathrm{SH} 2$ protein-3 (CIS3/SOCS3) inhibits Janus tyrosine kinase by binding through the $\mathrm{N}$-terminal kinase inhibitory region as well as SH2 domain. Genes Cells. (1999) 4:339-51. doi: 10.1046/j.1365-2443.1999.00263.x

36. Qing Y, Costa-Pereira AP, Watling D, Stark GR. Role of tyrosine 441 of interferon-gamma receptor subunit 1 in SOCS1-mediated attenuation of STAT1 activation. I Biol Chem. (2005) 280:1849-53. doi: 10.1074/jbc.M409863200

37. Fenner JE, Starr R, Cornish AL, Zhang J-G, Metcalf D, Schreiber RD, et al. Suppressor of cytokine signaling 1 regulates the immune response to infection by a unique inhibition of type I interferon activity. Nat Immunol. (2006) 7:33-9. doi: 10.1038/ni1287

38. Liau NPD, Laktyushin A, Lucet IS, Murphy JM, Yao S, Whitlock E, et al. The molecular basis of JAK/STAT inhibition by SOCS1. Nat Commun. (2018) 9:1558. doi: 10.1038/s41467-018-04013-1 
39. Mansell A, Smith R, Doyle SL, Gray P, Fenner JE, Crack PJ, et al. Suppressor of cytokine signaling 1 negatively regulates Toll-like receptor signaling by mediating Mal degradation. Nat Immunol. (2006) 7:14855. doi: 10.1038/ni1299

40. Kario E, Marmor MD, Adamsky K, Citri A, Amit I, Amariglio N, et al. Suppressors of cytokine signaling 4 and 5 regulate epidermal growth factor receptor signaling. J Biol Chem. (2005) 280:7038-48. doi: 10.1074/jbc.M408575200

41. Duncan SA, Baganizi DR, Sahu R, Singh SR, Dennis VA. SOCS proteins as regulators of inflammatory responses induced by bacterial infections: a review. Front Microbiol. (2017) 8:2431. doi: 10.3389/fmicb.2017. 02431

42. Yoshimura A, Nishinakamura H, Matsumura Y, Hanada T. Negative regulation of cytokine signaling and immune responses by SOCS proteins. Arthritis Res Ther. (2005) 7:100-10. doi: 10.1186/ar1741

43. Ram PA, Waxman DJ. SOCS/CIS protein inhibition of growth hormonestimulated STAT5 signaling by multiple mechanisms. J Biol Chem. (1999) 274:35553-61. doi: 10.1074/jbc.274.50.35553

44. Metcalf D, Greenhalgh CJ, Viney E, Willson TA, Starr R, Nicola NA, et al. Gigantism in mice lacking suppressor of cytokine signalling-2. Nature. (2000) 405:1069-73. doi: 10.1038/35016611

45. Greenhalgh CJ, Bertolino P, Asa SL, Metcalf D, Corbin JE, Adams TE, et al. Growth enhancement in suppressor of cytokine signaling 2 (SOCS-2)-deficient mice is dependent on signal transducer and activator of transcription 5b (STAT5b). Mol Endocrinol. (2002) 16:1394406. doi: 10.1210/mend.16.6.0845

46. Yoshimura A, Ito M, Chikuma S, Akanuma T, Nakatsukasa H. Negative regulation of cytokine signaling in immunity. Cold Spring Harbor Perspect Biol. (2018) 10:100-10. doi: 10.1101/cshperspect.a028571

47. Babon JJ, Kershaw NJ, Murphy JM, Varghese LN, Laktyushin A, Young $\mathrm{SN}$, et al. Suppression of cytokine signaling by SOCS3: characterization of the mode of inhibition and the basis of its specificity. Immunity. (2012) 36:239-50. doi: 10.1016/j.immuni.2011.12.015

48. Flowers LO, Johnson HM, Mujtaba MG, Ellis MR, Haider SMI, Subramaniam PS. Characterization of a peptide inhibitor of Janus kinase 2 that mimics suppressor of cytokine signaling 1 function. J Immunol. (2004) 172:7510-8. doi: 10.4049/jimmunol.172.12.7510

49. Waiboci LW, Ahmed CM, Mujtaba MG, Flowers LO, Martin JP, Haider, MI, et al. Both the suppressor of cytokine signaling 1 (SOCS-1) kinase inhibitory region and SOCS-1 mimetic bind to JAK2 autophosphorylation site: implications for the development of a SOCS-1 antagonist. J Immunol. (2007) 178:5058-68. doi: 10.4049/jimmunol.178.8.5058

50. Dalpke AH, Opper S, Zimmermann S, Heeg K. Suppressors of cytokine signaling (SOCS)-1 and SOCS-3 are induced by CpGDNA and modulate cytokine responses in APCs. J Immunol. (2001) 166:7082-9. doi: 10.4049/jimmunol.166.12.7082

51. Caballero P, Troncoso M, Patterson SI, López Gómez C, Fernandez R, Sosa MA. Neurotoxins from Clostridium botulinum (serotype A) isolated from the soil of Mendoza (Argentina) differ from the A-Hall archetype and from that causing infant botulism. Toxicon. (2016) 121:305. doi: 10.1016/j.toxicon.2016.08.010

52. Frobøse H, Rønn SG, Heding PE, Mendoza H, Cohen P, Mandrup-Poulsen $\mathrm{T}$, et al. Suppressor of cytokine signaling-3 inhibits interleukin-1 signaling by targeting the TRAF-6/TAK1 complex. Mol Endocrinol. (2006) 20:158796. doi: 10.1210/me.2005-0301

53. Zhou B, He Y, Zhang $\mathrm{X}$, Xu J, Luo Y, Wang Y, et al. Targeting mycobacterium protein tyrosine phosphatase B for antituberculosis agents. Proc Natl Acad Sci USA. (2010) 107:4573-8. doi: 10.1073/pnas.09091 33107

54. Lehmann U, Schmitz J, Weissenbach M, Sobota RM, Hortner M, Friederichs $\mathrm{K}$, et al. SHP2 and SOCS3 contribute to Tyr-759-dependent attenuation of interleukin-6 signaling through gp130. J Biol Chem. (2003) 278:66171. doi: $10.1074 /$ jbc.M210552200

55. Carow B, Rottenberg ME. SOCS3, a major regulator of infection and inflammation. Front Immunol. (2014) 5:58. doi: 10.3389/fimmu.2014.00058

56. Croker BA, Krebs DL, Zhang JG, Wormald S, Willson TA, Stanley EG, et al. SOCS3 negatively regulates IL-6 signaling in vivo. Nat Immunol. (2003) 4:540-5. doi: 10.1038/ni931
57. Lang R, Pauleau AL, Parganas E, Takahashi Y, Mages J, Ihle JN, et al. SOCS3 regulates the plasticity of gp130 signaling. Nat Immunol. (2003) 4:546-50. doi: 10.1038/ni932

58. Niwa Y, Kanda H, Shikauchi Y, Saiura A, Matsubara K, Kitagawa T, et al. Methylation silencing of SOCS-3 promotes cell growth and migration by enhancing JAK/STAT and FAK signalings in human hepatocellular carcinoma. Oncogene. (2005) 24:6406-17. doi: 10.1038/sj.onc.1208788

59. Ogata H, Chinen T, Yoshida T, Kinjyo I, Takaesu G, Shiraishi H, et al. Loss of SOCS3 in the liver promotes fibrosis by enhancing STAT3-mediated TGFbetal production. Oncogene. (2006) 25:2520-30. doi: 10.1038/sj.onc.1209281

60. Mui AL, Wakao H, Kinoshita T, Kitamura T, Miyajima A. Suppression of interleukin-3-induced gene expression by a C-terminal truncated Stat5: role of Stat5 in proliferation. EMBO J. (1996) 15:2425-33. doi: 10.1002/j.1460-2075.1996.tb00600.x

61. Sasi W, Sharma AK, Mokbel K. The role of suppressors of cytokine signalling in human neoplasms. Mol Biol Int. (2014) 2014:630797. doi: 10.1155/2014/630797

62. Tobelaim WS, Beaurivage C, Champagne A, Pomerleau V, Simoneau A, Chababi W, et al. Tumour-promoting role of SOCS1 in colorectal cancer cells. Sci Rep. (2015) 5:14301. doi: 10.1038/srep14301

63. Rawlings JS, Rosler KM, Harrison DA. The JAK/STAT signaling pathway. J Cell Sci. (2004) 117:1281-3. doi: 10.1242/jcs.00963

64. Guschin D, Rogers N, Briscoe J, Witthuhn B, Watling D, Horn F, et al. A major role for the protein tyrosine kinase JAK1 in the JAK/STAT signal transduction pathway in response to interleukin-6. EMBO J. (1995) 14:14219. doi: 10.1002/j.1460-2075.1995.tb07128.x

65. Posselt G, Schwarz H, Duschl A, Horejs-Hoeck J. Suppressor of cytokine signaling 2 is a feedback inhibitor of TLR-induced activation in human monocyte-derived dendritic cells. J Immunol. (2011) 187:287584. doi: 10.4049/jimmunol.1003348

66. Kinjyo I, Hanada T, Inagaki-Ohara K, Mori H, Aki D, Ohishi M, et al. SOCS1/JAB is a negative regulator of LPS-induced macrophage activation. Immunity. (2002) 17:583-91. doi: 10.1016/S1074-7613(02)00446-6

67. Kimura A, Naka T, Muta T, Takeuchi O, Akira S, Kawase I, et al. Suppressor of cytokine signaling-1 selectively inhibits LPS-induced IL-6 production by regulating JAK-STAT. Proc Natl Acad Sci USA. (2005) 102:1708994. doi: 10.1073/pnas.0508517102

68. Bode JG, Nimmesgern A, Schmitz J, Schaper F, Schmitt M, Frisch W, et al. LPS and TNFalpha induce SOCS3 mRNA and inhibit IL-6induced activation of STAT3 in macrophages. FEBS Lett. (1999) 463:36570. doi: 10.1016/S0014-5793(99)01662-2

69. Crespo A, Filla MB, Russell SW, Murphy WJ. Indirect induction of suppressor of cytokine signalling-1 in macrophages stimulated with bacterial lipopolysaccharide: partial role of autocrine/paracrine interferon-alpha/beta. Biochem J. (2000) 349:99-104. doi: 10.1042/bj3490099

70. Nakagawa R, Naka T, Tsutsui H, Fujimoto M, Kimura A, Abe T, et al. SOCS1 participates in negative regulation of LPS responses. Immunity. (2002) 17:677-87. doi: 10.1016/S1074-7613(02)00449-1

71. Hu J, Lou D, Carow B, Winerdal ME, Rottenberg M, Wikström $\mathrm{AC}$, et al. LPS regulates SOCS2 transcription in a type I interferon dependent autocrine-paracrine loop. PLoS ONE. (2012) 7:e30166. doi: 10.1371/journal.pone.0030166

72. Baetz A, Frey M, Heeg K, Dalpke AH. Suppressor of cytokine signaling (SOCS) proteins indirectly regulate toll-like receptor signaling in innate immune cells. J Biol Chem. (2004) 279:5470815. doi: 10.1074/jbc.M410992200

73. Manicassamy S, Pulendran B. Modulation of adaptive immunity with Toll-like receptors. Semin Immunol. (2009) 21:18593. doi: 10.1016/j.smim.2009.05.005

74. Fujimoto M, Naka T. SOCS1, a negative regulator of cytokine signals and TLR responses, in human liver diseases. Gastroenterol Res Pract. (2010) 2010. doi: 10.1155/2010/470468

75. Heeg K, Dalpke A. TLR-induced negative regulatory circuits: role of suppressor of cytokine signaling (SOCS) proteins in innate immunity. Vaccine. (2003) 21(Suppl. 2):S61-7. doi: 10.1016/S0264-410X(03)00202-0

76. Xu Y, Hu Y, Shi B, Zhang X, Wang J, Zhang Z, et al. HBsAg inhibits TLR9mediated activation and IFN-alpha production in plasmacytoid dendritic cells. Mol Immunol. (2009) 46:2640-6. doi: 10.1016/j.molimm.2009.04.031 
77. Yu C-F, Peng W-M, Schlee M, Barchet W, Eis-Hübinger AM, Kolanus W, et al. SOCS1 and SOCS3 Target IRF7 degradation to suppress TLR7mediated type I IFN production of human plasmacytoid dendritic cells. $J$ Immunol. (2018) 200:4024-35. doi: 10.4049/jimmunol.1700510

78. Paul AM, Acharya D, Le L, Wang P, Stokic DS, Leis AA, et al. TLR8 couples SOCS-1 and restrains TLR7-mediated antiviral immunity, exacerbating west nile virus infection in mice. J Immunol. (2016) 197:442535. doi: 10.4049/jimmunol.1600902

79. Zhang Y, Ma CJ, Ni L, Zhang CL, Wu XY, Kumaraguru U, et al. Cross-talk between programmed death-1 and suppressor of cytokine signaling-1 in inhibition of IL-12 production by monocytes/macrophages in hepatitis C virus infection. J Immunol. (2011) 186:3093-103. doi: 10.4049/jimmunol.1002006

80. Zhang W, Chen S, Zhang J, Wu Z, Wang M, Jia R, et al. Molecular identification and immunological characteristics of goose suppressor of cytokine signaling 1 (SOCS-1) in vitro and vivo following DTMUV challenge. Cytokine. (2017) 93:1-9. doi: 10.1016/j.cyto.2017.03.015

81. Arboleda JF, Fernandez GJ, Urcuqui-Inchima S. Vitamin D-mediated attenuation of miR-155 in human macrophages infected with dengue virus: Implications for the cytokine response. Infect Genet Evol. (2019) 69:1221. doi: 10.1016/j.meegid.2018.12.033

82. He Y, Zhang W, Zhang R, Zhang H, Min W. SOCS1 inhibits tumor necrosis factor-induced activation of ASK1-JNK inflammatory signaling by mediating ASK1 degradation. J Biol Chem. (2006) 281:555966. doi: 10.1074/jbc.M512338200

83. Gingras S, Parganas E, de Pauw A, Ihle JN, Murray PJ. Re-examination of the role of suppressor of cytokine signaling 1 (SOCS1) in the regulation of toll-like receptor signaling. J Biol Chem. (2004) 279:547027. doi: 10.1074/jbc.M411043200

84. Qin H, Wilson CA, Lee SJ, Benveniste EN. IFN-beta-induced SOCS-1 negatively regulates CD40 gene expression in macrophages and microglia. FASEB J. (2006) 20:985-7. doi: 10.1096/fj.05-5493fje

85. Lemke G, Rothlin CV. Immunobiology of the TAM receptors. Nat Rev Immunol. (2008) 8:327-36. doi: 10.1038/nri2303

86. Arima K, Nasu K, Narahara H, Fujisawa K, Matsui N, Miyakawa I. Effects of lipopolysaccharide and cytokines on production of RANTES by cultured human endometrial stromal cells. Mol Hum Reprod. (2000) 6:24651. doi: $10.1093 / \mathrm{molehr} / 6.3 .246$

87. Kawai T, Akira S. Signaling to NF-kappaB by Toll-like receptors. Trends Mol Med. (2007) 13:460-9. doi: 10.1016/j.molmed.2007.09.002

88. Wilson HM. SOCS proteins in macrophage polarization and function. Front Immunol. (2014) 5:357. doi: 10.3389/fimmu.2014.00357

89. Yasukawa H, Ohishi M, Mori H, Murakami M, Chinen T, Aki D, et al. IL-6 induces an anti-inflammatory response in the absence of SOCS3 in macrophages. Nat Immunol. (2003) 4:551-6. doi: 10.1038/ni938

90. El Kasmi KC, Holst J, Coffre M, Mielke L, de Pauw A, Lhocine N, et al. General nature of the STAT3-activated anti-inflammatory response. $J$ Immunol. (2006) 177:7880-8. doi: 10.4049/jimmunol.177.11.7880

91. Qin H, Holdbrooks AT, Liu Y, Reynolds SL, Yanagisawa LL, Benveniste EN. SOCS3 deficiency promotes M1 macrophage polarization and inflammation. J Immunol. (2012) 189:3439-48. doi: 10.4049/jimmunol.1201168

92. Cheon H, Rho YH, Choi SJ, Lee YH, Song GG, Sohn J, et al. Prostaglandin E2 augments IL-10 signaling and function. J Immunol. (2006) 177:1092100. doi: 10.4049/jimmunol.177.2.1092

93. Prêle CM, Keith-Magee AL, Yerkovich ST, Murcha M, Hart PH. Suppressor of cytokine signalling-3 at pathological levels does not regulate lipopolysaccharide or interleukin-10 control of tumour necrosis factoralpha production by human monocytes. Immunology. (2006) 119:817. doi: 10.1111/j.1365-2567.2006.02383.x

94. Qasimi P, Ming-Lum A, Ghanipour A, Ong CJ, Cox ME, Ihle J, et al. Divergent mechanisms utilized by SOCS3 to mediate interleukin-10 inhibition of tumor necrosis factor alpha and nitric oxide production by macrophages. J Biol Chem. (2006) 281:6316-24. doi: 10.1074/jbc.M508608200

95. Qin H, Wilson CA, Roberts KL, Baker BJ, Zhao X, Benveniste EN. IL10 inhibits lipopolysaccharide-induced CD40 gene expression through induction of suppressor of cytokine signaling-3. J Immunol. (2006) 177:7761-71. doi: 10.4049/jimmunol.177.11.7761
96. Liu X, Zhang Y, Yu Y, Yang X, Cao X. SOCS3 promotes TLR4 response in macrophages by feedback inhibiting TGF-beta1/Smad3 signaling. Mol Immunol. (2008) 45:1405-13. doi: 10.1016/j.molimm.2007. 08.018

97. Zhou X, Liu Z, Cheng X, Zheng Y, Zeng F, He Y. Socs1 and Socs3 degrades Traf6 via polyubiquitination in LPS-induced acute necrotizing pancreatitis. Cell Death Dis. (2015) 6:e2012. doi: 10.1038/cddis.2015.342

98. Zhang X, Wang Y, Yuan J, Li N, Pei S, Xu J, et al. Macrophage/microglial Ezh2 facilitates autoimmune inflammation through inhibition of Socs3. J Exp Med. (2018) 215:1365-82. doi: 10.1084/jem.20171417

99. Asari A, Kanemitsu T, Kurihara H. Oral administration of high molecular weight hyaluronan $(900 \mathrm{kDa})$ controls immune system via Toll-like receptor 4 in the intestinal epithelium. J Biol Chem. (2010) 285:247518. doi: 10.1074/jbc.M110.104950

100. Deb P, Dai J, Singh S, Kalyoussef E, Fitzgerald-Bocarsly P. Triggering of the cGAS-STING pathway in human plasmacytoid dendritic cells inhibits TLR9-mediated IFN production. J Immunol. (2020) 205:22336. doi: 10.4049/jimmunol.1800933

101. Kawai T, Akira S. The role of pattern-recognition receptors in innate immunity: update on Toll-like receptors. Nat Immunol. (2010) 11:37384. doi: 10.1038/ni.1863

102. Orabona C, Belladonna ML, Vacca C, Bianchi R, Fallarino F, Volpi C, et al. Cutting edge: silencing suppressor of cytokine signaling 3 expression in dendritic cells turns CD28-Ig from immune adjuvant to suppressant. $J$ Immunol. (2005) 174:6582-6. doi: 10.4049/jimmunol.174.11.6582

103. Orabona C, Pallotta MT, Volpi C, Fallarino F, Vacca C, Bianchi R, et al. SOCS3 drives proteasomal degradation of indoleamine 2,3-dioxygenase (IDO) and antagonizes IDO-dependent tolerogenesis. Proc Natl Acad Sci USA. (2008) 105:20828-33. doi: 10.1073/pnas.0810278105

104. Orr SJ, Morgan NM, Elliott J, Burrows JF, Scott CJ, McVicar DW, et al. CD33 responses are blocked by SOCS3 through accelerated proteasomal-mediated turnover. Blood. (2007) 109:1061-8. doi: 10.1182/blood-2006-05-023556

105. Emanuelli B, Peraldi P, Filloux C, Sawka-Verhelle D, Hilton D, Van Obberghen E. SOCS-3 is an insulin-induced negative regulator of insulin signaling. J Biol Chem. (2000) 275:15985-91. doi: 10.1074/jbc.275.21.15985

106. Rui L, Yuan M, Frantz D, Shoelson S, White MF. SOCS-1 and SOCS-3 block insulin signaling by ubiquitin-mediated degradation of IRS1 and IRS2. J Biol Chem. (2002) 277:42394-8. doi: 10.1074/jbc.C200444200

107. Senn JJ, Klover PJ, Nowak IA, Zimmers TA, Koniaris LG, Furlanetto RW, et al. Suppressor of cytokine signaling-3 (SOCS-3), a potential mediator of interleukin-6-dependent insulin resistance in hepatocytes. J Biol Chem. (2003) 278:13740-6. doi: 10.1074/jbc.M210689200

108. Shi H, Tzameli I, Bjørbaek C, Flier JS. Suppressor of cytokine signaling 3 is a physiological regulator of adipocyte insulin signaling. J Biol Chem. (2004) 279:34733-40. doi: 10.1074/jbc.M403886200

109. Lovibond AC, Haque SJ, Chambers TJ, Fox SW. TGF-beta-induced SOCS3 expression augments TNF-alpha-induced osteoclast formation. Biochem Biophys Res Commun. (2003) 309:762-7. doi: 10.1016/j.bbrc.2003.08.068

110. Nair S, Pandey AD, Mukhopadhyay S. The PPE18 protein of Mycobacterium tuberculosis inhibits NF- $\mathrm{\kappa B} /$ rel-mediated proinflammatory cytokine production by upregulating and phosphorylating suppressor of cytokine signaling 3 protein. J Immunol. (2011) 186:5413-24. doi: 10.4049/jimmunol.1000773

111. Koyama S, Ishii KJ, Coban C, Akira S. Innate immune response to viral infection. Cytokine. (2008) 43:336-41. doi: 10.1016/j.cyto.2008.07.009

112. Aoshi T, Koyama S, Kobiyama K, Akira S, Ishii KJ. Innate and adaptive immune responses to viral infection and vaccination. Curr Opin Virol. (2011) 1:226-32. doi: 10.1016/j.coviro.2011.07.002

113. O'Neill LAJ, Bowie AG. The family of five: TIR-domain-containing adaptors in Toll-like receptor signalling. Nat Rev Immunol. (2007) 7:35364. doi: 10.1038/nri2079

114. Jenkins KA, Mansell A. TIR-containing adaptors in Toll-like receptor signalling. Cytokine. (2010) 49:237-44. doi: 10.1016/j.cyto.2009.01.009

115. Dalpke A, Heeg K, Bartz H, Baetz A. Regulation of innate immunity by suppressor of cytokine signaling (SOCS) proteins. Immunobiology. (2008) 213:225-35. doi: 10.1016/j.imbio.2007.10.008

116. Colonna M. TLR pathways and IFN-regulatory factors: to each its own. Eur J Immunol. (2007) 37:306-9. doi: 10.1002/eji.200637009 
117. Takeuchi O, Akira S. Innate immunity to virus infection. Immunol Rev. (2009) 227:75-86. doi: 10.1111/j.1600-065X.2008.00737.x

118. Sakamoto H, Yasukawa H, Masuhara M, Tanimura S, Sasaki A, Yuge K, et al. A Janus kinase inhibitor, JAB, is an interferon-gamma-inducible gene and confers resistance to interferons. Blood. (1998) 92:166876. doi: 10.1182/blood.V92.5.1668

119. Song MM, Shuai K. The suppressor of cytokine signaling (SOCS) 1 and SOCS3 but not SOCS2 proteins inhibit interferon-mediated antiviral and antiproliferative activities. J Biol Chem. (1998) 273:3505662. doi: $10.1074 /$ jbc. 273.52 .35056

120. Gil MP, Bohn E, O'Guin AK, Ramana CV, Levine B, Stark GR, et al. Biologic consequences of Statl-independent IFN signaling. Proc Natl Acad Sci USA. (2001) 98:6680-5. doi: 10.1073/pnas.111163898

121. Honda K, Takaoka A, Taniguchi T. Type I interferon [corrected] gene induction by the interferon regulatory factor family of transcription factors. Immunity. (2006) 25:349-60. doi: 10.1016/j.immuni.2006.08.009

122. Baker BJ, Akhtar LN, Benveniste EN. SOCS1 and SOCS3 in the control of CNS immunity. Trends Immunol. (2009) 30:392-400. doi: 10.1016/j.it.2009.07.001

123. González-Navajas JM, Lee J, David M, Raz E. Immunomodulatory functions of type I interferons. Nat Rev Immunol. (2012) 12:12535. doi: 10.1038/nri3133

124. Luo X, Chen X-X, Qiao S, Li R, Xie S, Zhou X, et al. Porcine reproductive and respiratory syndrome virus enhances self-replication via AP-1-dependent induction of SOCS1. J Immunol. (2020) 204:394407. doi: 10.4049/jimmunol.1900731

125. Bode JG, Ludwig S, Ehrhardt C, Albrecht U, Erhardt A, Schaper F, et al. IFN-alpha antagonistic activity of $\mathrm{HCV}$ core protein involves induction of suppressor of cytokine signaling-3. FASEB J. (2003) 17:48890. doi: 10.1096/fj.02-0664fje

126. Yokota S-I, Yokosawa N, Okabayashi T, Suzutani T, Miura S, Jimbow K, et al. Induction of suppressor of cytokine signaling-3 by herpes simplex virus type 1 contributes to inhibition of the interferon signaling pathway. J Virol. (2004) 78:6282-6. doi: 10.1128/JVI.78.12.6282-6286.2004

127. Uetani K, Hiroi M, Meguro T, Ogawa H, Kamisako T, Ohmori Y, et al. Influenza A virus abrogates IFN-gamma response in respiratory epithelial cells by disruption of the Jak/Stat pathway. Eur J Immunol. (2008) 38:155973. doi: 10.1002/eji.200737045

128. Jia D, Rahbar R, Chan RWY, Lee SMY, Chan MCW, Wang BX, et al. Influenza virus non-structural protein 1 (NS1) disrupts interferon signaling. PLoS ONE. (2010) 5:e13927. doi: 10.1371/journal.pone.0013927

129. Zheng J, Yang P, Tang Y, Pan Z, Zhao D. Respiratory syncytial virus nonstructural proteins upregulate SOCS1 and SOCS3 in the different manner from endogenous IFN signaling. J Immunol Res. (2015) 2015:738547. doi: 10.1155/2015/738547

130. Wormald S, Hilton DJ. The negative regulatory roles of suppressor of cytokine signaling proteins in myeloid signaling pathways. Curr Opin Hematol. (2007) 14:9-15. doi: 10.1097/00062752-200701000-00004

131. Pothlichet J, Chignard M, Si-Tahar M. Cutting edge: innate immune response triggered by influenza A virus is negatively regulated by SOCS1 and SOCS3 through a RIG-I/IFNAR1-dependent pathway. J Immunol. (2008) 180:20348. doi: 10.4049/jimmunol.180.4.2034

132. Rothlin CV, Ghosh S, Zuniga EI, Oldstone MBA, Lemke G. TAM receptors are pleiotropic inhibitors of the innate immune response. Cell. (2007) 131:1124-36. doi: 10.1016/j.cell.2007.10.034

133. Chen J, Yang Y-F, Yang Y, Zou P, Chen J, He Y, et al. AXL promotes Zika virus infection in astrocytes by antagonizing type I interferon signalling. Nat Microbiol. (2018) 3:302-9. doi: 10.1038/s41564-017-0092-4

134. Bhattacharyya S, Zagórska A, Lew ED, Shrestha B, Rothlin CV, Naughton J, et al. Enveloped viruses disable innate immune responses in dendritic cells by direct activation of TAM receptors. Cell Host Microbe. (2013) 14:13647. doi: 10.1016/j.chom.2013.07.005

135. Okabayashi T, Kojima T, Masaki T, Yokota S-I, Imaizumi T, Tsutsumi H, et al. Type-III interferon, not type-I, is the predominant interferon induced by respiratory viruses in nasal epithelial cells. Virus Res. (2011) 160:3606. doi: 10.1016/j.virusres.2011.07.011

136. Wei H, Wang S, Chen Q, Chen Y, Chi X, Zhang L, et al. Suppression of interferon lambda signaling by SOCS-1 results in their excessive production during influenza virus infection. PLoS Pathog. (2014) 10:e1003845. doi: 10.1371/journal.ppat.1003845

137. Niwa M, Fujisawa T, Mori K, Yamanaka K, Yasui H, Suzuki Y, et al. IL-17A attenuates IFN- $\lambda$ expression by inducing suppressor of cytokine signaling expression in airway epithelium. J Immunol. (2018) 201:2392402. doi: 10.4049/jimmunol.1800147

138. Seong R-K, Lee JK, Shin OS. Zika virus-induction of the suppressor of cytokine signaling $1 / 3$ contributes to the modulation of viral replication. Pathogens. (2020) 9:163. doi: 10.3390/pathogens9030163

139. Koeberlein B, Hausen A, Bektas N, Zentgraf H, Chin R, Nguyen LT, et al. Hepatitis B virus overexpresses suppressor of cytokine signaling-3 (SOCS3) thereby contributing to severity of inflammation in the liver. Virus Res. (2010) 148:51-59. doi: 10.1016/j.virusres.2009.12.003

140. Song X-T, Evel-Kabler K, Rollins L, Aldrich M, Gao F, Huang XF, et al. An alternative and effective HIV vaccination approach based on inhibition of antigen presentation attenuators in dendritic cells. PLoS Med. (2006) 3:e11. doi: 10.1371/journal.pmed.0030011

141. Ryo A, Tsurutani N, Ohba K, Kimura R, Komano J, Nishi M, et al. SOCS1 is an inducible host factor during HIV-1 infection and regulates the intracellular trafficking and stability of HIV-1 Gag. Proc Natl Acad Sci USA. (2008) 105:294-9. doi: 10.1073/pnas.0704831105

142. Akhtar LN, Qin H, Muldowney MT, Yanagisawa LL, Kutsch O, Clements JE, et al. Suppressor of cytokine signaling 3 inhibits antiviral IFN-beta signaling to enhance HIV-1 replication in macrophages. J Immunol. (2010) 185:2393-404. doi: 10.4049/jimmunol.0903563

143. Miller RC, Schlaepfer E, Baenziger S, Crameri R, Zeller S, Byland R, et al. HIV interferes with SOCS-1 and -3 expression levels driving immune activation. Eur J Immunol. (2011) 41:1058-69. doi: 10.1002/eji.201041198

144. Yasukawa H, Yajima T, Duplain H, Iwatate M, Kido M, Hoshijima M, et al. The suppressor of cytokine signaling-1 (SOCS1) is a novel therapeutic target for enterovirus-induced cardiac injury. J Clin Investig. (2003) 111:46978. doi: 10.1172/JCI16491

145. Zhao D-C, Yan T, Li L, You S, Zhang C. Respiratory syncytial virus inhibits interferon-alpha-inducible signaling in macrophage-like U937 cells. J Infect. (2007) 54:393-8. doi: 10.1016/j.jinf.2006.06.005

146. Okumura A, Pitha PM, Yoshimura A, Harty RN. Interaction between Ebola virus glycoprotein and host toll-like receptor 4 leads to induction of proinflammatory cytokines and SOCS1. J Virol. (2010) 84:27-33. doi: 10.1128/JVI.01462-09

147. Pauli E-K, Schmolke M, Wolff T, Viemann D, Roth J, Bode JG, et al. Influenza A virus inhibits type I IFN signaling via NF-kappaBdependent induction of SOCS-3 expression. PLoS Pathog. (2008) 4:e1000196. doi: 10.1371/journal.ppat.1000196

148. Yokota S-I, Yokosawa N, Okabayashi T, Suzutani T, Fujii N. Induction of suppressor of cytokine signaling-3 by herpes simplex virus type 1 confers efficient viral replication. Virology. (2005) 338:173-81. doi: 10.1016/j.virol.2005.04.028

149. Frey KG, Ahmed CMI, Dabelic R, Jager LD, Noon-Song EN, Haider SM, et al. HSV-1-induced SOCS-1 expression in keratinocytes: use of a SOCS-1 antagonist to block a novel mechanism of viral immune evasion. J Immunol. (2009) 183:1253-62. doi: 10.4049/jimmunol.0900570

150. Choi EJ, Lee CH, Shin OS. Suppressor of cytokine signaling 3 expression induced by varicella-zoster virus infection results in the modulation of virus replication. Scand J Immunol. (2015) 82:337-44. doi: 10.1111/sji.12323

151. Kundu K, Dutta K, Nazmi A, Basu A. Japanese encephalitis virus infection modulates the expression of suppressors of cytokine signaling (SOCS) in macrophages: implications for the hosts' innate immune response. Cell Immunol. (2013) 285:100-10. doi: 10.1016/j.cellimm.2013.09.005

152. Michaud F, Coulombe F, Gaudreault E, Paquet-Bouchard C, RolaPleszczynski M, Gosselin J. Epstein-Barr virus interferes with the amplification of IFNalpha secretion by activating suppressor of cytokine signaling 3 in primary human monocytes. PLoS ONE. (2010) 5:e11908. doi: 10.1371/journal.pone.0011908

153. Akhtar LN, Benveniste EN. Viral exploitation of host SOCS protein functions. J Virol. (2011) 85:1912-21. doi: 10.1128/JVI.01857-10

154. Delgado-Ortega M, Marc D, Dupont J, Trapp S, Berri M, Meurens F. SOCS proteins in infectious diseases of mammals. Vet Immunol Immunopathol. (2013) 151. doi: 10.1016/j.vetimm.2012.11.008 
155. Collins AS, Ahmed S, Napoletano S, Schroeder M, Johnston JA, Hegarty JE, et al. Hepatitis $\mathrm{C}$ virus (HCV)-induced suppressor of cytokine signaling (SOCS) 3 regulates proinflammatory TNF- $\alpha$ responses. J Leukocyte Biol. (2014) 96:255-63. doi: 10.1189/jlb.2A1211-608RRRR

156. Convery O, Gargan S, Kickham M, Schroder M, O’Farrelly C, Stevenson NJ. The hepatitis $\mathrm{C}$ virus (HCV) protein, p7, suppresses inflammatory responses to tumor necrosis factor (TNF)- $\alpha$ signal transducer and activator of transcription (STAT) 3 and extracellular signal-regulated kinase (ERK)mediated induction of suppressor of cytokine signaling (SOCS)3. FASEB J. (2019) 33:8732-44. doi: 10.1096/fj.201800629RR

157. da Cunha Sousa LF, Rachid MA, Lima GK, de Miranda AS, de Carvalho Vilela M, Lacerda Queiroz N, et al. Suppressor of cytokine signaling 2 (SOCS2) contributes to encephalitis in a model of Herpes infection in mice. Brain Res Bull. (2016) 127:164-70. doi: 10.1016/j.brainresbull.2016.09.011

158. Wang X, Liu S, Zhou Z, Yan H, Xiao J. A herpes simplex virus type 2-encoded microRNA promotes tumor cell metastasis by targeting suppressor of cytokine signaling 2 in lung cancer. Tumour Biol. (2017) 39:1010428317701633. doi: 10.1177/1010428317701633

159. Aparecida Silva Barbosa A, Freitas Versiani A, Fonseca da Cunha Sousa L, Silva de Miranda A, Gasparini MR, Brant F, et al. Role of the suppressor of cytokine signaling 2 (SOCS2) during meningencephalitis caused by bovine herpesvirus 5 (BoHV-5). Comp Immunol Microbiol Infect Dis. (2016) 47:2631. doi: 10.1016/j.cimid.2016.05.003

160. Kedzierski L, Tate MD, Hsu AC, Kolesnik TB, Linossi EM, Dagley $\mathrm{L}$, et al. Suppressor of cytokine signaling (SOCS) 5 ameliorates influenza infection via inhibition of EGFR signaling. eLife. (2017) 6:e20444. doi: 10.7554/eLife.20444.025

161. Wu X, Jia R, Wang M, Chen S, Liu M, Zhu D, et al. Downregulation of microRNA-30a-5p contributes to the replication of duck enteritis virus by regulating Beclin-1-mediated autophagy. Virol J. (2019) 16:144. doi: 10.1186/s12985-019-1250-5

162. Bartel DP. MicroRNAs: target recognition and regulatory functions. Cell. (2009) 136:0-233. doi: 10.1016/j.cell.2009.01.002

163. Dang L, Teng M, Li H-Z, Ma S-M, Lu Q-X, Hao H-F, et al. Marek's disease virus type 1 encoded analog of miR-155 promotes proliferation of chicken embryo fibroblast and DF-1 cells by targeting hnRNPAB. Vet Microbiol. (2017) 207:210-8. doi: 10.1016/j.vetmic.2017.06.015

164. Deng Y, Yan Y, Tan KS, Liu J, Chow VT, Tao Z-Z, et al. MicroRNA$146 \mathrm{a}$ induction during influenza $\mathrm{H} 3 \mathrm{~N} 2$ virus infection targets and regulates TRAF6 levels in human nasal epithelial cells (hNECs). Exp Cell Res. (2017) 352:184-92. doi: 10.1016/j.yexcr.2017.01.011

165. Hazra B, Kumawat KL, Basu A. The host microRNA miR-301a blocks the IRF1-mediated neuronal innate immune response to Japanese encephalitis virus infection. Sci Signal. (2017) 10:eaaf5185. doi: 10.1126/scisignal. aaf5185

166. Smith JL, Jeng S, McWeeney SK, Hirsch AJ. A MicroRNA screen identifies the wnt signaling pathway as a regulator of the interferon response during flavivirus infection. J Virol. (2017) 91:e02388-16. doi: 10.1128/JVI.02388-16

167. Fu M, Wang B, Chen X, He Z, Wang Y, Li X, et al. MicroRNA gga-miR$130 \mathrm{~b}$ suppresses infectious bursal disease virus replication via targeting of the viral genome and cellular suppressors of cytokine signaling 5. J Virol. (2018) 92:e01646-17. doi: 10.1128/JVI.01646-17

168. Min C, Renyong J, Juan H, Xianglong W, Zhiqiang H, Xingcui Z, et al. Analysis of the microRNA expression profiles in DEF cells infected with duck Tembusu virus. Infect Gene Evolut. (2018) 63:12634. doi: 10.1016/j.meegid.2018.05.020

169. Wang B, Mengjiao F, Yanan L, Yongqiang W, Xiaoqi L, Hong C, et al. ggamiR-155 enhances type I interferon expression and suppresses infectious burse disease virus replication via targeting SOCS1 and TANK. Front Cell Infect Microbiol. (2018) 8:55. doi: 10.3389/fcimb.2018.00055

170. Zheng Z, Ke X, Wang M, He S, Li Q, Zheng C, et al. Human microRNA hsa-miR-296-5p suppresses enterovirus 71 replication by targeting the viral genome. J Virol. (2013) 87:5645-56. doi: 10.1128/JVI.02655-12

171. Escalera-Cueto M, Medina-Martínez I, del Angel RM, Berumen-Campos J, Gutiérrez-Escolano AL, Yocupicio-Monroy M. Let-7c overexpression inhibits dengue virus replication in human hepatoma Huh-7 cells. Virus Res. (2015) 196:105-12. doi: 10.1016/j.virusres.2014.11.010
172. Khongnomnan K, Makkoch J, Poomipak W, Poovorawan Y, Payungporn S. Human miR-3145 inhibits influenza A viruses replication by targeting and silencing viral PB1 gene. Exp Biol Med. (2015) 240:1630-9. doi: 10.1177/1535370215589051

173. Li L, Gao F, Jiang Y, Yu L, Zhou Y, Zheng H, et al. Cellular miR-130b inhibits replication of porcine reproductive and respiratory syndrome virus in vitro and in vivo. Sci Rep. (2015) 5:17010. doi: 10.1038/srep17010

174. Castrillón-Betancur JC, Urcuqui-Inchima S. Overexpression of miR-484 and miR-744 in Vero cells alters Dengue virus replication. Memor Instituto Oswaldo Cruz. (2017) 112:281-91. doi: 10.1590/0074-02760160404

175. Chang J, Guo J-T, Jiang D, Guo H, Taylor JM, Block TM. Liver-specific microRNA miR-122 enhances the replication of hepatitis $\mathrm{C}$ virus in nonhepatic cells. J Virol. (2008) 82:8215-23. doi: 10.1128/JVI.02575-07

176. Zhou Y, Liu Y, Yan H, Li Y, Zhang H, Xu J, et al. miR-281, an abundant midgut-specific miRNA of the vector mosquito Aedes albopictus enhances dengue virus replication. Parasites Vectors. (2014) 7:488. doi: 10.1186/s13071-014-0488-4

177. Scheel TKH, Luna JM, Liniger M, Nishiuchi E, Rozen-Gagnon $K$, Shlomai A, et al. A broad RNA virus survey reveals both miRNA dependence and functional sequestration. Cell Host Microbe. (2016) 19:40923. doi: 10.1016/j.chom.2016.02.007

178. Fu M, Wang B, Chen X, He Z, Wang Y, Li X, et al. gga-miR-454 suppresses infectious bursal disease virus (IBDV) replication via directly targeting IBDV genomic segment B and cellular Suppressors of Cytokine Signaling 6 (SOCS6). Virus Res. (2018) 252:29-40. doi: 10.1016/j.virusres.2018.05.015

179. Duan X, Zhao M, Li X, Gao L, Cao H, Wang Y, et al. gga-miR-27b$3 p$ enhances type I interferon expression and suppresses infectious bursal disease virus replication via targeting cellular suppressors of cytokine signaling 3 and 6 (SOCS3 and 6). Virus Res. (2020) 281:197910. doi: 10.1016/j.virusres.2020.197910

180. Xu G, Yang F, Ding CL, Wang J, Ren H. MiR-221 accentuates IFN?s antiHCV effect by downregulating SOCS1 and SOCS3. Virology. (2014) 462 3:343-50. doi: 10.1016/j.virol.2014.06.024

181. Sharma N, Kumawat KL, Rastogi M, Basu A, Singh SK. Japanese encephalitis virus exploits the microRNA-432 to regulate the expression of suppressor of cytokine signaling (SOCS) 5. Sci Rep. (2016) 6:27685. doi: 10.1038/srep27685

182. Ma Y, Wang C, Xue M, Fu F, Zhang X, Li L, et al. The coronavirus transmissible gastroenteritis virus evades the type I interferon response through IRE1 $\alpha$-mediated manipulation of the MicroRNA miR-30a5p/SOCS1/3 axis. J Virol. (2018) 92:e00728-18. doi: 10.1128/JVI.00728-18

183. Ahmed CMI, Dabelic R, Martin JP, Jager LD, Haider SM, Johnson HMJ. Enhancement of antiviral immunity by small molecule antagonist of suppressor of cytokine signaling. I Immunol. (2010) 185:110313. doi: 10.4049/jimmunol.0902895

184. Ahmed CM, Rea D, Kennedy BS, Joseph L, Johnson HMJ. A SOCS1/3 antagonist peptide protects mice against lethal infection with influenza A virus. Front Immunol. (2015) 6:574. doi: 10.3389/fimmu.2015.00574

185. Lui PY, Jin DY, Stevenson NJ. MicroRNA: master controllers of intracellular signaling pathways. Cell Mol Life Sci. (2015) 72:353142. doi: 10.1007/s00018-015-1940-0

186. Persico M, Capasso M, Persico E, Svelto M, Russo R, Spano D, et al. Suppressor of cytokine signaling 3 (SOCS3) expression and hepatitis C virusrelated chronic hepatitis: Insulin resistance and response to antiviral therapy. Hepatology. (2007) 46:1009-15. doi: 10.1002/hep.21782

187. Yoshikawa T, Takata A, Otsuka M, Kishikawa T, Kojima K, Yoshida H, et al. Silencing of microRNA-122 enhances interferon- $\alpha$ signaling in the liver through regulating SOCS3 promoter methylation. Sci Rep. (2012) 2:637. doi: 10.1038/srep00637

188. El-Saadany S, Ziada DH, El Bassat H, Farrag W, El-Serogy H, Eid M, et al. The role of hepatic expression of STAT1, SOCS3 and PIAS1 in the response of chronic hepatitis C patients to therapy. Can J Gastroenterol. (2013) 27:e13-17. doi: 10.1155/2013/562765

189. Pellegrini M, Calzascia T, Toe JG, Preston SP, Lin AE, Elford AR, et al. IL-7 engages multiple mechanisms to overcome chronic viral infection and limit organ pathology. Cell. (2011) 144:601-13. doi: 10.1016/j.cell.2011.01.011

190. Shouda T, Yoshida T, Hanada T, Wakioka T, Oishi M, Miyoshi K, et al. Induction of the cytokine signal regulator SOCS3/CIS3 as a therapeutic 
strategy for treating inflammatory arthritis. J Clin Invest. (2001) 108:17818. doi: 10.1172/JCI13568

191. Mahller YY, Sakthivel B, Baird WH, Aronow BJ, Hsu YH, Cripe TP, et al. Molecular analysis of human cancer cells infected by an oncolytic HSV-1 reveals multiple upregulated cellular genes and a role for SOCS1 in virus replication. Cancer Gene Ther. (2008) 15:733-41. doi: 10.1038/cgt.2008.40

192. Sakurai H, Tashiro K, Kawabata K, Yamaguchi T, Sakurai F, Nakagawa S, et al. Adenoviral expression of suppressor of cytokine signaling-1 reduces adenovirus vector-induced innate immune responses. J Immunol. (2008) 180:4931-8. doi: 10.4049/jimmunol.180.7.4931

193. Chikuma S, Kanamori M, Mise-Omata S, Yoshimura A. Suppressors of cytokine signaling: potential immune checkpoint molecules for cancer immunotherapy. Cancer Sci. (2017) 108:574-80. doi: 10.1111/cas. 13194

194. Ashenafi S, Aderaye G, Bekele A, Zewdie M, Aseffa G, Hoang AT, et al. Progression of clinical tuberculosis is associated with a Th2 immune response signature in combination with elevated levels of SOCS3. Clin Immunol. (2014) 151:84-99. doi: 10.1016/j.clim.2014.01.010

195. Sharma J, Larkin J III. Therapeutic implication of SOCS1 modulation in the treatment of autoimmunity and cancer. Front Pharmacol. (2019) 10:324. doi: 10.3389/fphar.2019.00324

196. Zhang J, Li H, Yu JP, Wang SE, Ren XB. Role of SOCS1 in tumor progression and therapeutic application. Int J Cancer. (2012) 130:197180. doi: $10.1002 /$ ijc. 27318

197. Jiang M, Zhang WW, Liu P, Yu W, Liu T, Yu J. Dysregulation of SOCSmediated negative feedback of cytokine signaling in carcinogenesis and its significance in cancer treatment. Front Immunol. (2017) 8:70. doi: $10.3389 /$ fimmu. 2017.00070
198. Flowers LO, Subramaniam PS, Johnson HM. A SOCS-1 peptide mimetic inhibits both constitutive and IL-6 induced activation of STAT3 in prostate cancer cells. Oncogene. (2005) 24:2114-20. doi: 10.1038/sj.onc. 1208437

199. Liang P, Cheng SH, Cheng CK, Lau KM, Lin SY, Chow EY, et al. Platelet factor 4 induces cell apoptosis by inhibition of STAT3 via up-regulation of SOCS3 expression in multiple myeloma. Haematologica. (2013) 98:28895. doi: 10.3324/haematol.2012.065607

200. Xiong H, Du W, Zhang YJ, Hong J, Su WY, Tang JT, et al. Trichostatin A, a histone deacetylase inhibitor, suppresses JAK2/STAT3 signaling via inducing the promoter-associated histone acetylation of SOCS1 and SOCS3 in human colorectal cancer cells. Mol Carcinog. (2012) 51:17484. doi: $10.1002 / \mathrm{mc} .20777$

201. Stone L. Putting a SOCS in prostate cancer. Nat Rev Urol. (2019) 16:147. doi: 10.1038/s41585-019-0151-0

Conflict of Interest: The authors declare that the research was conducted in the absence of any commercial or financial relationships that could be construed as a potential conflict of interest.

Copyright $\odot 2020$ Huang, Liu, Cheng, Wang, Cui, Huang, Zhu, Chen, Liu, Zhao, Wu, Yang, Zhang, Ou, Mao, Gao, Yu, Tian, Liu, Zhang, Yin, Jing, Chen and Jia. This is an open-access article distributed under the terms of the Creative Commons Attribution License (CC BY). The use, distribution or reproduction in other forums is permitted, provided the original author(s) and the copyright owner(s) are credited and that the original publication in this journal is cited, in accordance with accepted academic practice. No use, distribution or reproduction is permitted which does not comply with these terms. 